\title{
MiR-183/-96/-182 cluster is up-regulated in most breast cancers and increases cell proliferation and migration
}

\author{
Pei Li ${ }^{1}$, Cheng Sheng ${ }^{1}$, Lingling Huang ${ }^{1}$, Hui Zhang ${ }^{2}$, Lihua Huang ${ }^{2}$, Zeneng Cheng ${ }^{1}$ and Qubo Zhu ${ }^{*}$
}

\begin{abstract}
Introduction: The miR-183/-96/-182 cluster is a conserved polycistronic microRNA (miRNA) cluster which is highly expressed in most breast cancers. Although there are some sporadic reports which demonstrate the importance of each miRNA in this cluster in breast cancer, the biological roles of this cluster as a whole and its regulation mechanisms in breast cancer are still unclear. We compared the expression of this cluster in different cancer types, analyzed the regulation mechanism of this cluster, identified new target genes, and examined the impact of this cluster on breast cancer cells.
\end{abstract}

Methods: The miRNA level was detected by LNA-based northern blot and Real-time PCR, and was also analyzed from TCGA dataset. Bioinformatics research and luciferase assay were applied to find the promoter regions and transcription factors. To investigate the biological effects of the miR-183/-96/-182 cluster in breast cancer, we generated miR-96, miR-182 and miR-183 overexpression stable cell lines to check the overdose effects; we also used miR-Down ${ }^{\text {TM }}$ antagomir for each miRNA as well as miR-183/-96/-182 cluster sponge lentivirus to check the knockdown effects. Growth, migration, cell cycle profile and survival of these cells was then monitored by colony formation assay, MTT assay, cell wound healing assay, flow cytometry and microscopy. The target gene was validated by Real-time PCR, luciferase assay, Western blot and Phalloidin/DAPI counterstaining.

Results: The miR-183/-96/-182 cluster was highly expressed in most breast cancers, and its transcription is disordered in breast cancer. The miR-183/-96/-182 cluster was transcribed in the same pri-miRNA and its transcription was regulated by ZEB1 and HSF2. It increased breast cell growth by promoting more rapid completion of mitosis, promoted cell migration and was essential for cell survival. MiR-183 targeted the RAB21 mRNA directly in breast cancer.

Conclusion: The miR-183/-96/-182 cluster is up-regulated in most breast cancer. It functions as an oncogene in breast cancer as it increases cell proliferation and migration.

\section{Introduction}

Breast cancer is a family of diseases that involve unregulated breast epithelial cell growth and division, which is caused by many different carcinogenic factors. The exact cause of breast cancer is unclear. Many risk factors may increase the chance of having breast cancer, such as endocrine disorders, genetic mutations and declines in immune function. However, unregulated mammary epithelial cell proliferation and apoptosis, which are caused

\footnotetext{
*Correspondence: biqbz@hotmail.com

${ }^{1}$ The School of Pharmaceutical Sciences in Central South University, 172

Tongzipo Road, Yuelu District, Changsha 410013, Hunan, China

Full list of author information is available at the end of the article
}

by an accumulation of gene mutations and by dysregulated gene expression, is the essential reason for breast cancer. As numerous genes are predicted to be regulated by microRNA (miRNA), mammary tumorigenesis and metastasis is likely to be regulated by several tissuespecific miRNAs.

The miR-183/-96/-182 cluster is a highly conserved polycistronic miRNA cluster which was first identified by $\mathrm{Dr} \mathrm{Xu}$ in sensory organs [1]. Members of this cluster are located within a $5-\mathrm{kb}$ region on human chromosome $7 \mathrm{q} 32.2$ and are transcribed in the same direction from telomere to centromere. Previous studies showed that the $m i R-183 /-96 /-182$ cluster is abnormally expressed in 
a variety of tumors and is directly involved in human cancers. But the role of this miRNA cluster in tumors is still unclear. It may function as an oncogene or tumor suppressor gene, depending on the type, location and stage of the cancer. We summarize its reported functions in cancers and its target genes in Table 1.

The miR-183/-96/-182 cluster has not yet been extensively studied in breast cancer. Forkhead box O (FOXO) proteins, which are a family of tumor suppressor transcription factors involved in cell growth, proliferation, differentiation, and longevity, are the main targets for this cluster in breast cancer. Both FOXO1 and FOXO3a are regulated by $m i R-96$ and $m i R-182[5,6]$. It seems that this miRNA cluster functions as onco-microRNA in breast cancer. However, in 2010, Lowery et al. reported that miR-183 inhibits cell migration in breast cancer by repressing Ezrin, which plays a key role in cell-surface structure adhesion, migration, and organization [12]. These conflicting results may be ascribed to two reasons. One possibility is that these three miRNAs are transcribed or processed in different way and they function separately and differently; the other possibility is that this cluster plays different roles in different breast cancer types. In fact, the level of $m i R-183$ was lower in estrogen receptor $(E R)$-positive breast tumors compared to $E R$ - negative tumors, and higher in human epidermal growth factor receptor-2 (HER2)/neu-receptor-positive tumors compared to HER2/neu-receptor-negative tumors [12], suggesting the roles of miR-183 in different breast cancer cells are different.

Recently, attention has focused on the target genes of these miRNAs; however, little is known about the regulation mechanism of the miRNA cluster itself. Most miRNA genes are transcribed by RNA polymerase II [15], which means miRNA biogenesis is controlled elaborately through various regulatory pathways just as protein-coding mRNAs. Chromatin structure analysis, genomic and RNA sequence analysis and RNA polymerase II chromatin immuneprecipitation assays have been applied to predict the transcription start site (TSS) and promoter region of miRNAs [16-19], but few results have been confirmed by experiments. The Ozsolak [16], Wang [18], and Chien [19] laboratories predicted that the TSS of miR-183/-96/-182 was 5068 bp, 5200 bp and 5207 bp upstream of the miR-183 precursor, respectively. However, the promoter region of $m i R-183 /-96 /-182$ and the transcription regulators remain unknown.

Here, we investigated the function of the miR-183/$96 /-182$ cluster in breast cancer. We found that the miR183/-96/-182 cluster was highly expressed in most breast

Table 1 Role of miR-183/-96/-182 in cancer based on recent publications within the last five years

\begin{tabular}{|c|c|c|c|c|c|}
\hline miRNA & Oncogene/tumor suppressor & Cancer type & Function & Target genes & Reference \\
\hline miR-96 & Oncogene & Hepatocellular carcinoma & $\begin{array}{l}\text { Increases proliferation and } \\
\text { colony formation }\end{array}$ & FOXO1, FOXO3a & [2] \\
\hline miR-96 & Oncogene & Prostate cancer & Inhibits zinc uptake & ZIP1, ZIP3, ZIP7, ZIP9, ZnT1, ZnT7 & [3] \\
\hline \multicolumn{6}{|l|}{ miR-182 } \\
\hline \multicolumn{6}{|l|}{ miR-183 } \\
\hline miR-96 & Oncogene & Medullo-blastoma & Inhibits apoptosis, destroys & See reference & [4] \\
\hline miR-182 & & & $\begin{array}{l}\text { DNA repair, promotes } \\
\text { cell migration }\end{array}$ & & \\
\hline \multicolumn{6}{|l|}{ miR-183 } \\
\hline miR-96 & Oncogene & Breast cancer & Induces proliferation & FOXO3a & [5] \\
\hline $\operatorname{miR}-96$ & Oncogene & Breast cancer & Increases cell number & FOXO1 & [6] \\
\hline \multicolumn{6}{|l|}{ miR-182 } \\
\hline miR-182 & Oncogene & Glioma & Promotes glioma cell aggression & $C Y L D$ & [7] \\
\hline miR-182 & Oncogene & Melanoma & $\begin{array}{l}\text { Promotes cell migration } \\
\text { and survival }\end{array}$ & $\mathrm{FOXO3}$ & [8] \\
\hline \multirow[t]{2}{*}{ miR-183 } & Oncogene & Synovial sarcoma & Promotes tumor cell migration & EGR1 & [9] \\
\hline & & & & PTEN & \\
\hline miR-183 & Oncogene & Hepatocellular carcinoma & $\begin{array}{l}\text { linhibits TGF-beta1-induced } \\
\text { apoptosis }\end{array}$ & PDCD4 & [10] \\
\hline miR-96 & Tumor suppressor & Pancreatic cancer & $\begin{array}{l}\text { Decreases cell invasion, } \\
\text { migration and tumor growth }\end{array}$ & KRAS & [11] \\
\hline miR-183 & Tumor suppressor & Breast cancer & Inhibits migration & Ezrin & [12] \\
\hline miR-183 & Tumor suppressor & Osteosarcoma & Inhibits migration and invasion & Ezrin & [13] \\
\hline miR-182 & Tumor suppressor & Lung cancer & Inhibits cancer cell proliferation & RGS17 & [14] \\
\hline
\end{tabular}


cancers. These three miRNAs were transcribed in the same pri-miRNA and this miRNA cluster was regulated by $H S F 2$ and ZEB1. We also demonstrated that the miR$183 /-96 /-182$ cluster functioned as an onco-miRNA in breast cancer. Overexpression of the miR-183/-96/-182 cluster increased the cell proliferation rate and promoted cell migration while inhibition of the miR-183/-96/-182 cluster decreased cell growth rate, and even induced cell death. MiR-183 targeted RAB21 directly in breast cancer and accumulated nucleus number aberration cells. Our results suggested that the $m i R-183 /-96 /-182$ cluster plays an important role in tumorigenesis and in the migration of breast cancer cells.

\section{Methods}

\section{Clinical cancer samples and cell lines}

All cancer samples were obtained from the Affiliated Tumor Hospital of XiangYa Medical School of Central South University, and stored at $-80^{\circ} \mathrm{C}$ until analyzed. All experiments were conducted in accordance with the Declaration of Helsinki and were approved by the Xiangya Hospital Medical Ethics Committee in Central South University.

Breast cancer cell lines MCF-7,MDA-MB-231,SK-BR-3, T47D, ZR-75-1, MCF-10A and human embryonic kidney cell HEK-293 were used in the study. MCF-7 and MDAMB-231 were obtained from NeuronBiotech (Shanghai, China). SK-BR-3, T47D, ZR-75-1 and MCF-10A were obtained from Dingguo, Co. (Beijing, China). HEK-293 was obtained from Xiangya experiment center (Changsha, China). All the cells were cultured in complete DMEM high glucose medium (Hyclone, Logan, UT, USA) supplemented with $10 \%$ FBS (Hyclone) and 1\% penicillin and streptomycin sulfate (Solarbia, Co., Beijing, China). Cells were incubated at $37^{\circ} \mathrm{C}$ with $5 \% \mathrm{CO}_{2}$ and medium was changed every 2 or 3 days.

\section{Virion and cell line constructions}

To establish the miRNA overexpression cell lines, partial mir-96, mir-182 and mir-183 pri-microRNA sequences flanked by EcoRI and AgeI restriction sites were inserted into the CMV promoter of lentivirus infectious virions pLKD-CMV-G\&PR-U6-shRNA (Hpcoo3) (Additional file 1: Figure S1A). MCF-7 or T47D cells were infected with these viruses and selected under the pressure of $1 \mu \mathrm{g} / \mathrm{ml}$ puromycin (Invitrogen, San Diego, CA, USA). The green fluorescent protein (GFP) signal of the infected cells was detected under microscope (Additional file 1: Figure S1B), and the expression of the miR-183/-96/-182 cluster in each cell line was measured by reverse transcription (RT)PCR (Additional file 1: Figure S1C).

To disrupt the activity of the miR-183/-96/-182 cluster, we generated miR-183/-96/-182 cluster sponge lentivirus virion. Basically, 10 copies each of complementary sequences to $m i R-183, m i R-96$ and $m i R-182$, each with mismatches at positions 9 to 12 for improved stability $[20,21]$, were introduced into the pLOV-CMV-eGFPEF1a-PuroR lentivirus infective virion (Additional file 2: Figure S2). A moderate multiplicity of infection (MOI) of 1 was used for transduction. The infection efficiency and cell morphology were monitored under microscope every day. After 3 days of transduction, cells were collected for cell cycle analysis and RNAs were collected for realtime PCR.

To research the function of transcription factors, the coding sequences of HSF2 and ZEB1 flanked by XhoI and KpnI restriction sites were inserted into vector GV219. The plasmids were transfected into MCF-7 cells and the cells were selected with a culture medium containing $600 \mu \mathrm{g} / \mathrm{ml} \mathrm{G418-Geneticin} \mathrm{(GenView,} \mathrm{Galveston,}$ TX, USA) for 2 months.

\section{LNA-based Northern Blotting}

Total RNAs were extracted from cancer samples with the mirVanaTM miR isolation kit and $10 \mu \mathrm{g}$ of total RNA was used for each assay. All procedures followed manufacturer's instructions for the miRCURY LNA ${ }^{\mathrm{m}}$ microRNA detection probes (Exiqon, Woburn, MA, USA). After fractionation by electrophoresis on a denaturing $12 \%$ polyacrylamide gel containing $8 \mathrm{M}$ urea, RNAs were transferred to Nytran $\mathrm{N}$ membrane (Amersham Biosciences, Piscataway, NJ, USA) and fixed by UV crosslinking. Blots were prehybridized for $1 \mathrm{~h}$ at $45^{\circ} \mathrm{C}$ in PerfectHyb ${ }^{\text {Tw }}$ Plus Hybridization Buffer (Sigma, St Louis, MO, USA) and hybridized overnight at $45^{\circ} \mathrm{C}$ in hybridization buffer containing $0.1 \mathrm{nM}$ probe, then washed twice for 30 minutes at $65^{\circ} \mathrm{C}$ in $0.1 \mathrm{SSC} / 0.1 \%$ SDS. As the probes were $5^{\prime}$-DIG labeled, we detected the signal by PhototopeR-Star Kit (New England BioLabs Inc, Ipswich, MA, USA), and the densities were quantified by the Image J program. Because the $m i R-183$, $m i R-96$ and $m i R-182$ sequences are similar, we tested the probe specificities before doing the experiments (Additional file 3: Figure S3). Mimic oligonucleotides were designed based on miRNA sequences registered in the miRBase Sequence Database (see Additional file 4: Table S1).

\section{RT-PCR and real-time PCR}

For mRNA RT-PCR and real-time PCR, total RNAs were extracted from cancer samples or cultured cells with Trigol (Dingguo, Co.) reagent. Primer sets were designed within the exon junction areas listed in Additional file 4: Table S2. For miRNA real-time PCR, miRNAs were extracted from cells using a mirVana miRNA isolation kit (Ambion, Austin, TX, USA). All primers, including the YRBIO $^{\mathrm{mm}}$ miRNA qPCR Detection primer sets and U6 snRNA PCR primer set were purchased from Yingrun Biotechnology (Changsha, China). 
In brief, mRNA and miRNA were reverse-transcribed with an M-MLV First Strand kit (Invitrogen). Then 50 ng cDNA was mixed with All-in-one ${ }^{\mathrm{mm}}$ qPCR Mix (Genecopoeia, Rockville, MD, USA) and the target gene primer set (final concentration: $1 \mu \mathrm{M}$ for each primer) to produce a $20-\mu \mathrm{l}$ reaction mixture. All real-time PCR experiments were carried out with an ABI Step One Plus Real-time PCR System (Applied Biosystems, Carlsbad, CA, USA). All real-time PCR reactions were done in triplicates, and the average $\Delta \mathrm{CT}$ ( $\Delta$ cycle threshold) for the triplicates was used in subsequent analysis.

\section{Plasmid, miR-Down ${ }^{\mathrm{TM}}$ antagomir and transfection}

Large-scale plasmids were extracted by PureYield ${ }^{\text {mix }}$ Plasmid Midiprep System (Promega, Madison, WI, USA), and small-scale plasmids were extracted by Mini DNA purification kit (Dingguo). Chemically modified antisense oligonucleotides (miR-Down ${ }^{\mathrm{Tm}}$ antagomir, GenePharm Co. Ltd, Shanghai, China) were used to inhibit miR-96, miR-182 and $m i R-183$ expression. A scrambled oligonucleotide was used as control. Plasmid and miR-Down ${ }^{\mathrm{Tm}}$ antagomir transfections were conducted with Lipofectamine ${ }^{\mathrm{Tw}} 2000$ reagent (Invitrogen).

\section{Luciferase reporter assays}

For promoter analysis, promoter region sequences or their mutants flanked by XhoI and KpnI restriction sites were inserted into the upstream region of luciferase reporter gene in pGL3-Basic vector (Promega). MCF-7 cells were transfected with $200 \mathrm{ng}$ reporter construct and $1 \mu \mathrm{g}$ GV219 vector with or without transcription factor sequence. Also, $40 \mathrm{ng}$ of pRL-CMV-Renilla plasmid was transfected as an internal control.

For target analysis, $33 \mathrm{bp}$ of $R A B 213^{\prime}$-UTRs including the seed sequence were flanked by $\mathrm{XbaI}$ and FseI restriction sites and inserted between the Luciferase coding sequence and SV40 polyadenylation element in pGL3Promoter vector (Promega). HEK-293 cells were transfected with $200 \mathrm{ng}$ reporter construct and $1 \mu \mathrm{g} \mathrm{Hpcoo3}$ vector with or without partial pri-microRNA sequence of miR-183/-96/-182 cluster. Also, 40 ng of pRL-CMVRenilla plasmid was transfected as an internal control.

The luciferase reporter assays (Promega) were performed $48 \mathrm{~h}$ after transfection, and luciferase activity was determined with a GloMax 20/20 Luminometer (Promega). Relative luciferase activities were calculated as ratios of firefly to renilla luciferase activities.

\section{Assays: 3-(4, 5-dimethyl-2-thiazolyl)-2, 5-diphenyl-2H- tetrazolium bromide (MTT)}

Cells were seeded on 96-well plates $\left(5 \times 10^{3}\right.$ cells per well) and incubated for $24 \mathrm{~h}$ in $0.2 \mathrm{ml}$ medium. After reaction with $20 \mu \mathrm{l} 5 \mathrm{mg} / \mathrm{ml}$ sterile MTT (Sigma) for $4 \mathrm{~h}$ at $37^{\circ} \mathrm{C}$, culture media was removed and $150 \mu \mathrm{l}$ of dimethyl sulphoxide (DMSO) was added. The absorbance was measured with the ELISA reader (BioTek, Vermont, VT, USA) at $490 \mathrm{~nm}$ and $540 \mathrm{~nm}$ and the reactions were performed in triplicates.

\section{Cell wound-healing assays}

Cells were seeded on 6 -well plates $\left(5 \times 10^{5}\right.$ cells per well $)$ and incubated for $24 \mathrm{~h}$. Adherent cell monolayers were scratched with a 10- $\mu$ l pipette tip and cultured in $2 \mathrm{ml}$ DMEM high-glucose medium without FBS or antibiotics. Cell migration was monitored under microscopy later.

\section{Colony formation assays}

The culture dish was covered by $2 \mathrm{ml}$ bottom gel $(0.5 \%$ basic agar in RPMI medium 1640 (Invitrogen) supplemented with $10 \% \mathrm{FBS}$ and $1 \%$ penicillin/streptomycin) and $1.5 \mathrm{ml}$ top gel (0.7\% agar in RPMI-1640 medium supplemented with $10 \%$ FBS and $1 \%$ penicillin/streptomycin) mixed with 10,000 cells. Cells were incubated for 16 days and the colonies were stained with $0.5 \mathrm{ml} 0.005 \%$ crystal violet overnight followed by washing with PBS (Hyclone) three times. The pictures of cell colonies were taken by a digital camera.

\section{Cell cycle analysis}

Cells were digested with $0.05 \%$ trypsin (Thermo Scientific, Logan, UT, USA) for 2 minutes to dissociate them from the plates. After fixation in $70 \%$ pre-chilled $\left(-20^{\circ} \mathrm{C}\right)$ ethanol in $\mathrm{PBS}$ at $4^{\circ} \mathrm{C}$ overnight, cells were treated with $10 \mu \mathrm{g} / \mathrm{ml}$ of RNase (Auragene, Co., Shenzhen, China) in PBS at $37^{\circ} \mathrm{C}$ for $2 \mathrm{~h}$ and stained with $50 \mu \mathrm{g} / \mathrm{ml}$ of propidium iodide (PI) (Sigma) for 5 minutes. Flow cytometry was conducted on a BD FACSCalibur flow cytometer (BD Biosciences, Franklin, IN, USA) and data were analyzed by ModFit LT software.

\section{Western blotting}

Total proteins were lysed in RIPA buffer $(150 \mathrm{mM} \mathrm{NaCl}$, $0.1 \%$ SDS, $0.5 \%$ sodium deoxycholate, $1 \%$ NP-40 and 50 $\mathrm{mM}$ Tris- $\mathrm{HCl}, \mathrm{pH}$ 7.6) with a proteinase inhibitor cocktail (Roche, Mannheim, Germany). After separation by $15 \%$ polyacrylamide gels and transfer to $0.45 \mu \mathrm{m}$ membrane (Millipore, Billerica, MA, USA), proteins were detected by anti-RAB21 (Abcam, HongKong, China) and anti- $\beta$-tubulin (Sigma) antibodies.

Phalloidin and 4,6-diamidino-2-phenylindole (DAPI) staining For imaging of fixed cells, cells were seeded on acidwashed, glass coverslips coated with $5 \mu \mathrm{g} / \mathrm{ml}$ of collagen. Cells were then fixed with $3.7 \%$ paraformaldehyde in PBS permeabilized with $0.2 \%$ Triton X-100 in PBS for 15 minutes. Then we co-stained the cells with fluorescein isothiocyanate (FITC)-conjugated phalloidin (Beyotime, Shangai, China) to detect the F-actin, and with DAPI 
(Invitrogen) to detect the nuclear. Coverslips were mounted with Microscopy Aquatex ${ }^{\oplus}$ mounting medium (Merck, Darmstadt, Germany), and then detected under the Leica Tcs-sp5-II confocal microscope (Leica, Wetzlar, Germany).

\section{Statistical analysis}

Data were expressed as means $\pm \mathrm{SD}$, and the statistical software SPSS 11.5 (IBM, Armonk, NY, USA) was used for analysis of variance (ANOVA) and analysis using Student's $t$-test. Statistical probability $(P)$ in tables, figures, and figure legends are expressed as follows: ${ }^{*} P<0.05$, **P $P<0.01$, ** $P<0.001$.

\section{Results}

The miR-183/-96/-182 cluster was highly expressed in most breast cancers

Six different tumors and their normal adjacent tissues (NAT) were collected from the Hunan Tumor Hospital.
Breast cancer and liver cancer tumors were available from two patients, and other types of cancer were from one patient. The miRNAs were detected by LNA-based northern blot. We found that $m i R-96, m i R-182$ and $m i R$ 183 expression levels were dramatically higher in tumors compared to the normal adjacent tissues in breast, lung and liver cancers. MiR-96 was also expressed in thyroid and larynx cancers, but the expression differences between tumors and their normal adjacent tissues were not obvious. The expressions of these three miRNAs were undetectable in other carcinoma tissues (Figure 1A). We then performed an analysis of miRNA expression data detected by either IlluminaGA_miRNASeq or IlluminaHiseq_miRNASeq in breast invasive carcinoma from the TCGA dataset. From 102 matched pairs of samples (Additional file 5), we found the expression levels of $m i R-96, m i R-182$ and $m i R-183$ in tumor samples were increased 8.4 ( \pm 1.1)-fold, $4.2 \pm(1.1)$-fold and $7.5 \pm(1.1)$ fold respectively compared to the matched normal
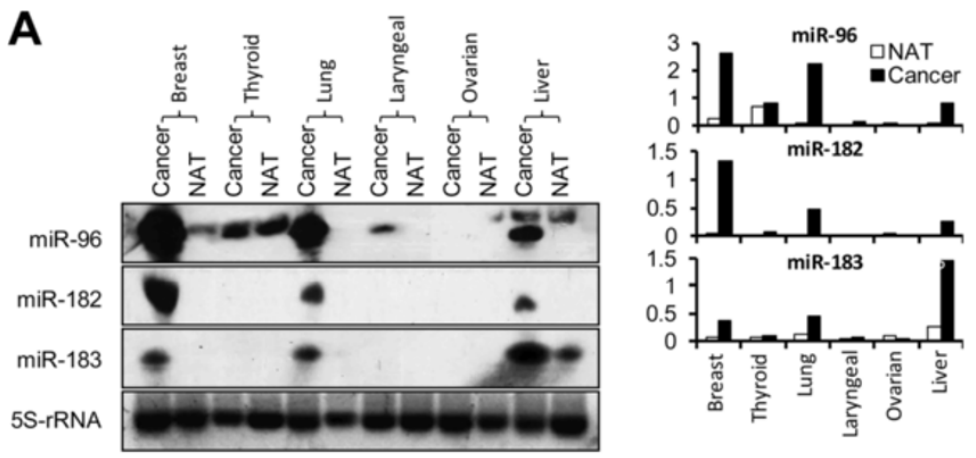

B

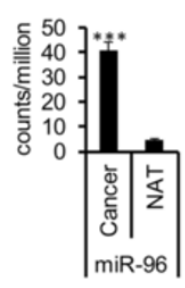

NAT

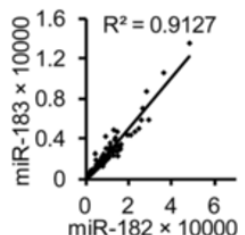

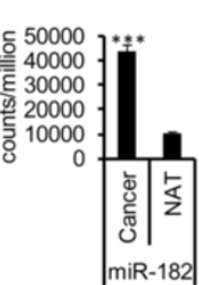

miR-182|

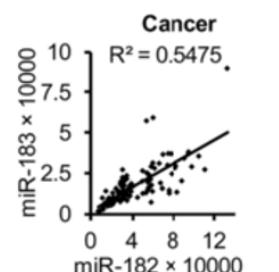

C

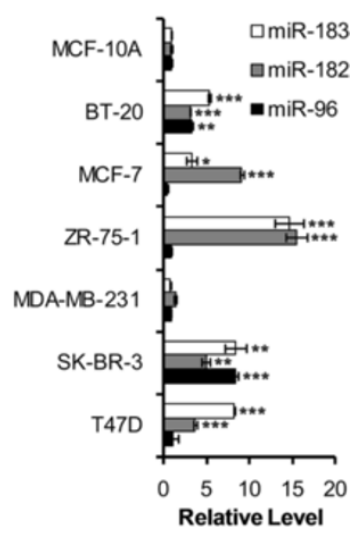

Figure 1 MiR-183/-96/-182 cluster is highly expressed in breast cancer cells. (A) Detection of miR-183/-96/-182 cluster miRNAs by LNA-based northern blot in different cancer samples and their normal adjacent tissues (NAT). Left panel shows the northern blot analysis of miR-183/-96/-182 cluster miRNAs; 5S-r RNA was used as an internal control. Left panel is the quantification of selected miRNAs by the Image J program. The results were normalized to the 5S-r RNA. (B) Statistical analysis of miRNA expression data in breast invasive carcinoma from the TCGA dataset: upper panel compares the miRNA expression levels between tumor samples and their matched normal samples; lower panel analyzes the correlation between miR-182 and miR-183 levels in normal and tumor samples. Error bars indicate SD ( $\mathrm{n}=102$ ). (C) Quantification of the miR-183/-96/-182 cluster miRNAs by real-time PCR in different breast cancer cell lines. MCF-10A cell was used as control. U6 snRNA was used as internal control. Error bars indicate SD $(n=3)$. 
samples (Figure 1B, upper panel). Another interesting phenomenon was that the expression levels of miR-183 and miR-182 were highly correlated in normal samples $\left(R^{2}=0.9127\right)$, but the correlation dropped dramatically in tumor samples $\left(R^{2}=0.5475\right)$, which indicated that the transcription pattern was changed in breast cancer (Figure 1B, lower panel).

Because breast cancer is a heterogeneous disease comprising different subtypes that vary significantly with regard to clinical features and molecular markers, we compared the miRNAs expression levels in different breast cancers based on their clinical features, surface markers and clinical stages. From 990 samples (Additional file 6), we found the expressions of $m i R-96$ and $m i R-183$ were lower in lobular carcinoma than in ductal carcinoma and other types of carcinoma, but the expression of miR182 was not correlated with the clinical features (Table 2). The levels of $m i R-96$ and $m i R-183$ were also lower in $\mathrm{ER}+$ and PR+ cancers than in ER- and PR- cancers, but miR-182 was almost the same, even slightly higher in ER+ cancers. We did not find any correlation between the miR-183/-96/-182 cluster level and the HER2/neu receptor (Table 3). The expression of $m i R-183 /-96 /-182$ cluster was not correlated with clinical stages, as all the three miRNAs remained the same in all clinical stages (Table 4). To divide the breast cancer samples into different subtypes, the following surface markers were used: luminal A (ER+ and/or PR+, HER2-), luminal B (ER+ and/or PR+, HER2+), basal-like (ER-, PR-, HER2-), HER2-enriched (ER-, PR-, HER2+) [22]. We found miR-96 and miR-183 levels were higher in HER2-enriched breast cancers than other types. In basal-like breast cancers, miR-182 was lower but miR-183 was higher comparing to other types of breast cancer (Table 5). All these data indicated that although miR-183/-96/-182 cluster was up-regulated in most breast cancers, its expression pattern was slightly different in different breast cancer subtypes.

To confirm our findings, we also compared the miRNAs levels in different breast cancer cell lines based on their ER, PR and HER2/neu receptor status. T47D (ER+/PR+/HER2-), SK-BR-3 (ER-/PR-/HER2+), MDMBA-231 (ER-/R-/HER2-), ZR-75-1 (ER+/PR+/HER2+), BT-20 (ER-/PR-/HER2-) and MCF-7 (ER+/PR+/HER2-) cell lines were tested in this study and normal human mammary epithelial cell line (MCF-10A) were used as a control. We found that, relative to MCF-10A cell expression levels, miR-96 was only up-regulated in SK-BR-3 and BT-20 cells; miR-182 and miR-183 were up-regulated in most of the breast cancer cell lines except MD-MBA-231; none of the miRNAs in the miR-183/-96/-182 cluster was increased in MD-MBA-231 cell line (Figure 1C). Our data were similar to those reported by Riaz et al. [23], who also found that the highest expression of miR-96 was SK-BR-3 and the lowest expression of all these three miRNAs was MD-MBA-231 among these six breast cancer cell lines. We chose MCF-7 and T47D cells for further studies because their miR-183/-96/-182 clusters were highly expressed and they were easy to culture.

\section{MiR-183/-96/-182 cluster was transcribed in the same pri-miRNA and was regulated by ZEB1 and HSF2}

To study the regulation mechanism of the miR-183/-96/182 cluster itself, we first analyzed the upstream sequence of the miR-183/-96/-182 cluster through the ENCODE project. We found a highly conserved region from 5054 bp to 9324 bp upstream of the human miR-183 precursor (Figure 2A, red box). The ENCODE project displayed the acetylation of histone $\mathrm{H} 3$ and the transcription factor chromatin immunoprecipitation (Chip) data to find the active regulatory elements. H3K27Ac histone marks were enriched in this region, which demonstrates that this region contains active regulatory elements. Transcription factor Chip data also showed that this region was easily pulled down with transcription factors. Altogether the information suggested that the promoter region and TSS of the $m i R-183 /-96 /-182$ cluster is in this region.

Then, to check whether miR-183, miR-96 and miR-182 were transcribed in the same pri-miRNA or separately, we designed a series of primer pairs (Additional file 4: Table S3) to determine whether the corresponding regions of DNA were transcribed. Each primer pair spanned about $1600 \mathrm{bp}$ and all the primer pairs divided the genomic DNA surrounding the miR-183/-96/-182 cluster (5352 bp upstream to 5893 downstream of human miR-183 precursor) into eight regions. From 5 '-end to 3 '-end, they were named Seq\#1, Seq\#2 ... Seq\#8 (their relative locations are showed in Figure 2B, upper panel). Total RNAs were extracted from MCF-7, T47D and MCF10A cell lines.

Table 2 Correlation between miRNA levels and clinical features

\begin{tabular}{llll}
\hline & miR-96 (per million) & miR-182 (per million) & miR-183 (per million) \\
\hline Ductal $(\mathbf{n}=\mathbf{7 3 4})$ & $43.0 \pm 34.4$ & $48741.7 \pm 33619.5$ & $20501.7 \pm 15436.4$ \\
Lobular $(\mathbf{n}=\mathbf{1 6 3})$ & $36.6 \pm 28.8^{*}$ & $51136.1 \pm 37893.2$ & $14014.1 \pm 9845.4^{* * *}$ \\
Mixed $(\mathbf{n}=\mathbf{2 8})$ & $37.6 \pm 26.1$ & $44265.7 \pm 22469.4$ & $15781.5 \pm 10831.5$ \\
Other $(\mathbf{n}=\mathbf{6 3})$ & $49.1 \pm 41.2$ & $50700.0 \pm 38025.3$ & $19988.6 \pm 17839.2$ \\
\hline
\end{tabular}

The expression of each miRNA in the miR-183/-96/182 cluster in different breast cancer subtypes is based on their clinical features: Patient number is indicated in the first column. Data are presented as mean \pm SD. Statistical probability $(P)$ was expressed as ${ }^{*} P<0.05,{ }^{* * *} P<0.001$. 
Table 3 Correlation between miRNA levels and surface markers

\begin{tabular}{llll}
\hline & miR-96 (per million) & miR-182 (per million) & miR-183 (per million) \\
\hline ER- $(\mathbf{n}=\mathbf{1 8 5})$ & $46.9 \pm 37.1$ & $42764.4 \pm 29615.6$ & $23463.0 \pm 18606.7$ \\
ER $+(\mathbf{n}=\mathbf{6 4 3})$ & $40.5 \pm 32.2^{*}$ & $49378.5 \pm 32671.3^{*}$ & $17756.8 \pm 12451.0^{* * *}$ \\
PR- $(\mathbf{n}=\mathbf{2 6 5})$ & $45.6 \pm 34.7$ & $45513.2 \pm 32873.7$ & $22037.2 \pm 16212.9$ \\
PR $+(\mathbf{n}=\mathbf{5 6 1})$ & $40.2 \pm 32.8^{*}$ & $49013.4 \pm 31716.4$ & $17628.8 \pm 12993.5^{* * *}$ \\
HER2- $(\mathbf{n}=\mathbf{5 1 2})$ & $40.7 \pm 34.5$ & $47943.7 \pm 32825.1$ & $18532.7 \pm 14331.1$ \\
HER2+ $(\mathbf{n}=\mathbf{1 4 4})$ & $41.8 \pm 32.5$ & $44664.8 \pm 28806.9$ & $19404.0 \pm 14591.3$ \\
\hline
\end{tabular}

The expression of each miRNA in the miR-183/-96/182 cluster in different breast cancer subtypes based on their surface markers: Patient number is indicated in the first column. Data are presented as mean $\pm \mathrm{SD}$. Statistical probability $(P)$ was expressed as ${ }^{*} P<0.05,{ }^{* * *} P<0.001$. ER, estrogen receptor; $P R$, progesterone receptor; HER, human epidermal growth factor receptor.

MCF-7 genomic DNA was used as a positive control to check the efficiency of primer pairs. RT-PCR data showed that RNA were correctly transcribed from Seq\#2 to Seq\#7 (Seq\#8 was a non-specific band because the size is incorrect) (Figure 2B). This data indicated that $m i R-183$, miR96 and $m i R-182$ were transcribed in the same pri-miRNA and the start site of this pri-microRNA was 5352 bp to $3991 \mathrm{bp}$ upstream of the $m i R-183$ precursor, and the transcript termination site was 289 bp to 1352 bp downstream of the miR-182 precursor. Several papers also predicted that the TSS of miR-183/-96/-182 was between $5068 \mathrm{bp}$ and 5207 bp upstream of human miR-183 precursor $[16,18,19]$. We could not tell whether the transcription pattern was changed in cancer cells from this experiment because the PCR method is not linear.

Next we sought to determine how this pri-miRNA was regulated. To find the promoter region, we generated luciferase reporters with $1 \mathrm{~kb}, 2 \mathrm{~kb}, 3 \mathrm{~kb}$ and $4 \mathrm{~kb}$ DNA fragments within the conserved region (4263 bp to $8533 \mathrm{bp}$ upstream of the mouse miR-183 precursor, corresponding to $5054 \mathrm{bp}$ to $9324 \mathrm{bp}$ upstream of the human miR-183 precursor. Figure 2A, red box), named upstream $1 \mathrm{~kb}$, upstream $2 \mathrm{~kb}$, upstream $3 \mathrm{~kb}$ and upstream $4 \mathrm{~kb}$ respectively. These luciferase assay results showed that the upstream 1 $\mathrm{kb}$, upstream $2 \mathrm{~kb}$ and upstream $3 \mathrm{~kb}$ fragments increased luciferase activity approximately 30 -fold compared with the empty vector. No significant difference was detected among upstream $1 \mathrm{~kb}$, upstream $2 \mathrm{~kb}$ and upstream $3 \mathrm{~kb}$. Upstream $4 \mathrm{~kb}$ increased luciferase activity 17 -fold compared with the empty vector, which was much lower than the other three reporters (Figure 2C). These data demonstrate that most active regulatory elements were located within $1 \mathrm{~kb}$ from the upstream of TSS region, and some repression elements were located between $3 \mathrm{~kb}$ and $4 \mathrm{~kb}$ from upstream of the TSS region.

To find the transcription factors regulating the miR183/-96/-182 cluster, we used the online bioinformatics tools TFSEARCH to predict the transcription factor binding sites within $1 \mathrm{~kb}$ upstream from the TSS region of the miR-183/-96/-182 cluster. Four DNA sequences were predicted to be recognized by ZEB1, HSF2, ZEB1 and $S p 1$ respectively (Figure $3 \mathrm{~A}$ ). We mutated the candidate transcription factor binding sites and performed the luciferase assay again. The luciferase activities of the $H S F 2$ and the first ZEB1 mutant were significantly lower than upstream $1 \mathrm{~kb}$ (by about 50\%), which suggested that these two sites were indeed transcription factor binding sites and that HSF2 and ZEB1 were two important transcription factors in cluster transcriptional regulation (Figure 3B). Therefore, we cloned HSF2 and ZEB1 into the GV219 vector and co-transfected the transcription factors and the native or mutated upstream $1 \mathrm{~kb}$ luciferase reporters together into the MCF-7 cells. We found that HSF2 alone upregulated the luciferase activity of native upstream $1 \mathrm{~kb} 1.9$ ( \pm 0.3)-fold, but had no effect on upstream $1 \mathrm{~kb}$ with a mutant HSF2 site. ZEB1 upregulated the luciferase activity of native upstream $1 \mathrm{~kb} 6.7( \pm 0.7)$ fold, but had no effect on ZEB1 mutant upstream $1 \mathrm{~kb}$ reporter. There was no synergetic effect of these two genes, as co-transfection of the two genes only upregulated the luciferase activity of native upstream $1 \mathrm{~kb} 2.5$ ( \pm 0.2 )-fold (Figure 3C).

Table 4 Correlation between miRNA levels and clinical stages

\begin{tabular}{llll}
\hline & miR-96 (per million) & miR-182 (per million) & miR-183 (per million) \\
\hline Stage I $(\mathbf{n}=\mathbf{1 6 8})$ & $39.6 \pm 31.5$ & $48001.8 \pm 29113.8$ & $17783.2 \pm 14764.5$ \\
Stage II $(\mathbf{n}=\mathbf{5 6 5})$ & $44.1 \pm 35.7$ & $49987.5 \pm 37649.4$ & $19919.8 \pm 15730.5$ \\
Stage III $(\mathbf{n}=\mathbf{2 2 2})$ & $38.6 \pm 30.2$ & $47865.8 \pm 29685.2$ & $18164.0 \pm 11961.5$ \\
Stage IV and X $(\mathbf{n}=\mathbf{3 3})$ & $44.2 \pm 34.2$ & $47104.5 \pm 29358.6$ & $22262.4 \pm 17792.5$ \\
\hline
\end{tabular}

The expression of each miRNA in the miR-183/-96/182 cluster in different breast cancer subtypes based on their clinical stages: Patient number is indicated in the first column. Data are presented as mean \pm SD. 
Table 5 miRNA levels in different molecular subtypes of breast cancer

\begin{tabular}{llll}
\hline & miR-96 (per million) & miR-182 (per million) & miR-183 (per million) \\
\hline HER2-enriched $(\mathbf{n}=\mathbf{3 4})$ & $55.0 \pm 46.9^{*}$ & $49308.2 \pm 31807.6$ & $24494.0 \pm 16871.2^{*}$ \\
Basal $(\mathbf{n}=\mathbf{1 0 5})$ & $42.3 \pm 30.6$ & $38971.0 \pm 24170.6^{* *}$ & $21991.9 \pm 16491.6^{*}$ \\
Luminal A $(\mathbf{n}=\mathbf{4 0 6})$ & $40.4 \pm 35.5$ & $50347.2 \pm 34351.2$ & $17668.1 \pm 13604.2$ \\
Luminal B $(\mathbf{n}=\mathbf{1 0 9})$ & $38.0 \pm 25.5$ & $43312.6 \pm 27928.1$ & $17779.5 \pm 13563.3$ \\
\hline
\end{tabular}

The expression of each miRNA in miR-183/-96/182 cluster in different molecular subtypes of breast cancer: Patient number is indicated in the first column. Data are presented as mean $\pm \mathrm{SD}$. The following markers were used to determine breast cancer subtypes: luminal $\mathrm{A}$ (estrogen receptor (ER)+ and/or progesterone receptor (PR)+, human epidermal growth factor (HER)2-), luminal B (ER + and/or PR+, HER2+), basal-like (ER-, PR- , HER2-), HER2-enriched (ER-, PR-, HER2+). Statistical probability $(P)$ was expressed as ${ }^{*} P<0.05$, ${ }^{* *} P<0.01$.

To further confirm our results, we transfected the HSF2 and ZEB1 overexpression plasmids into MCF-7 cells, and then selected for stable cell lines with G418. Then we compared the expression levels of miR-96, $m i R-182$ and $m i R-183$ in stable overexpression cell lines with the control cell line, which was transfected with empty vector. Real-time PCR data showed that miR-96 and miR-183 were increased 2.7- to 3.8-fold compared to the control cell line, but miR-182 did not increase very much (Figure 3D). We think the reason why miR-182 did not increase much is because miR-182 is far from the transcript regulation area. Although these three miRNAs are transcribed in the same pri-microRNA, the ending of this pri-microRNA is not always the same. Sometimes, it will end before miR-182 transcription. This result might explain why miR-182 only increased $4.2( \pm 1.1)$-fold in tumor samples, but miR-96 and miR-183 increased 8.4 $( \pm 1.1)$ - and $7.5( \pm 1.1)$-fold in tumor samples. It could also explain why the expression levels of miR-183 and miR-182 correlated more strongly sin normal samples, but

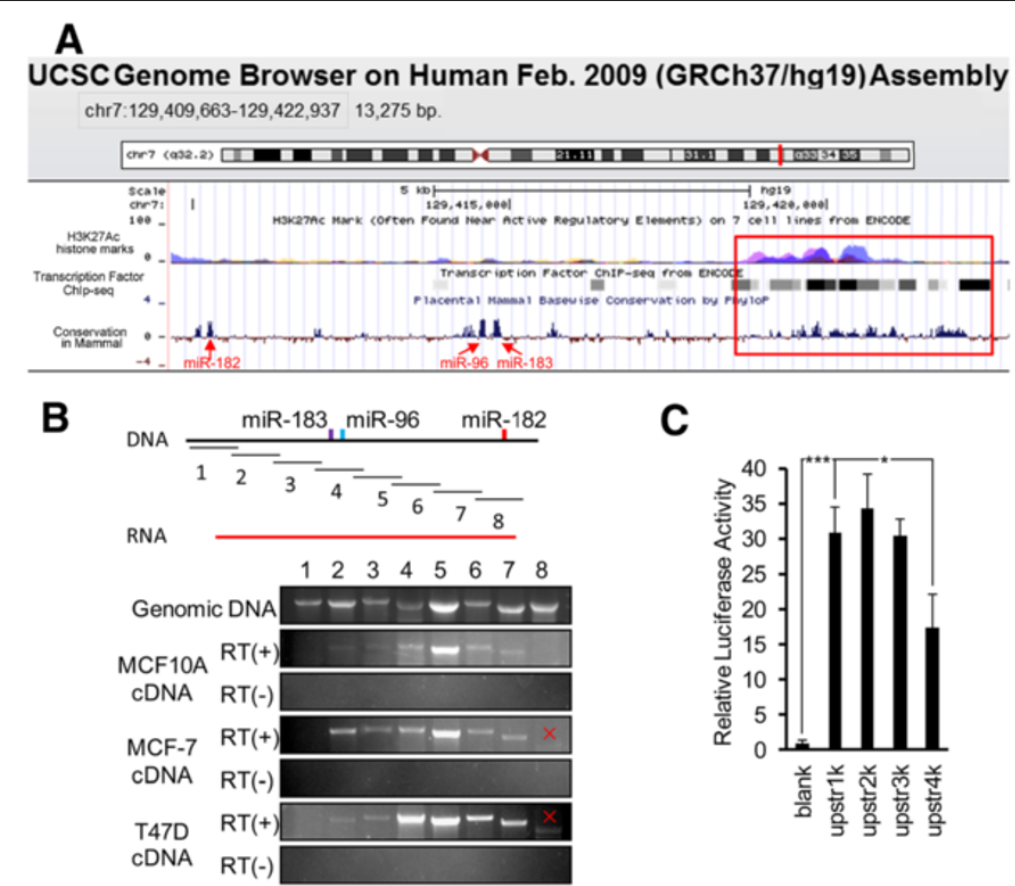

Figure 2 Analysis of the miR-183/-96/-182 cluster promoter region. (A) ENCODE project analysis of the upstream sequence of the miR-183/-96/-182 cluster: sequences in the red box represent the region from 5054 bp to 9324 bp upstream of the human miR-183 precursor that is highly conserved and enriched for 3K27Ac histone marks. (B) Fragmental reverse transcription (RT)-PCR demonstrated that the miR-183/-96/-182 cluster was transcribed in the same pri-miRNA: upper panel shows a schematic representation of the location of RT-PCR fragments and the miR-183/-96/-182 cluster in chromosome; lower panel shows the RT-PCR results of MCF-10A, MCF-7 and T47D cell CDNAs. Genomic DNA of MCF-7 cell was used as a positive control to check the efficiency of primer pairs; RNA sample, which did not undergo the reverse transcription reaction, was used as a negative control. (C) Luciferase assay indicated that most active regulatory elements were located within $1 \mathrm{~kb}$ from upstream of the TSS region of miR-183/-96/-182 cluster. All luciferase activities were normalized to those obtained with the pGL3-Basic vector alone. Error bars represent SD $(n=4)$. 

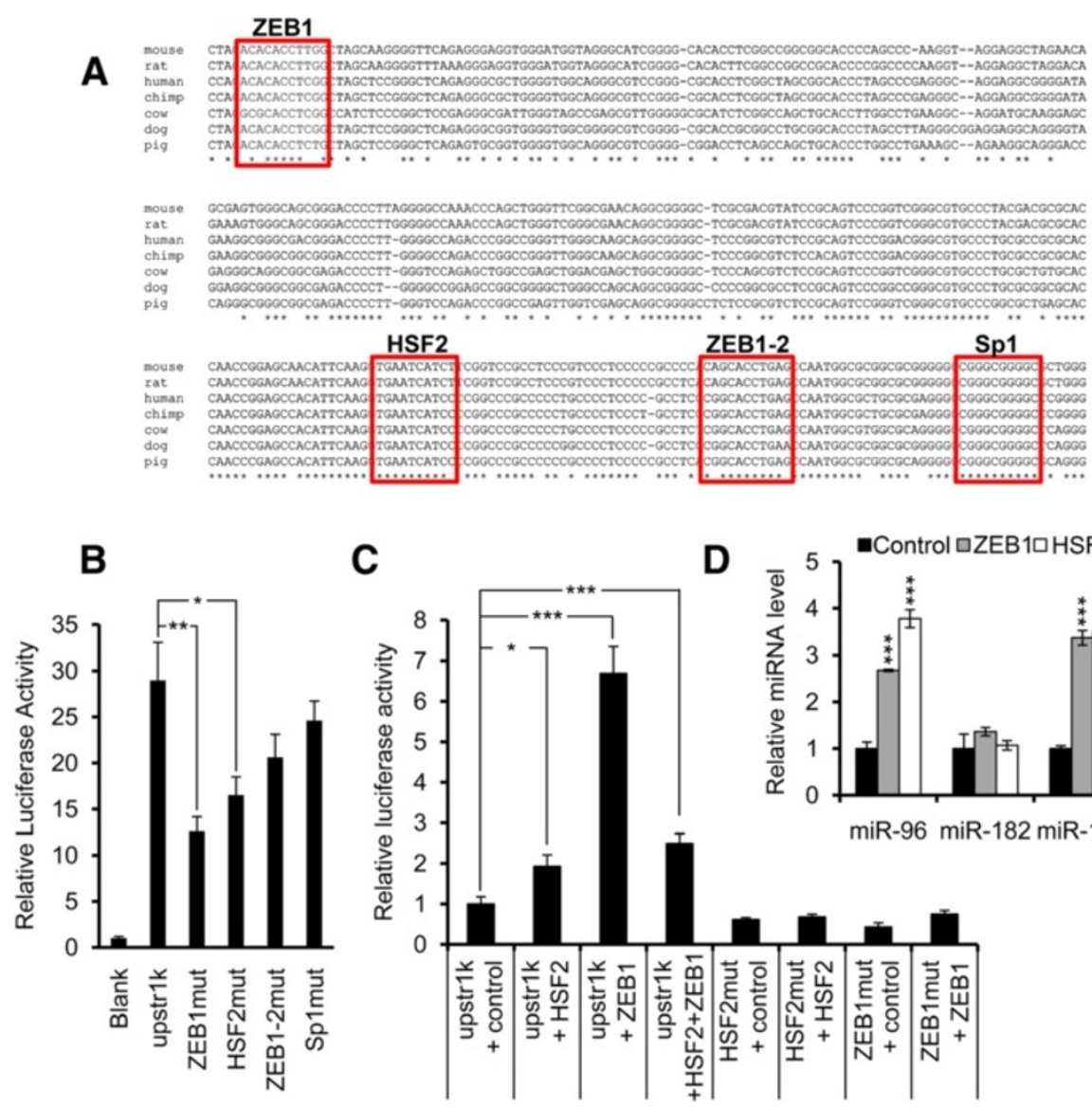

\section{C}

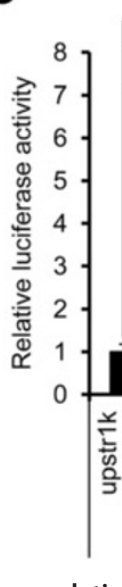

D

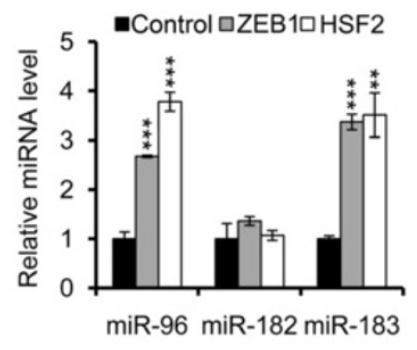

Figure 3 Identification of the transcription factors regulating the miR-183/-96/-182 cluster. (A) Phylogenetic analysis demonstrated that there were four conserved transcription factor binding sites located within the $1 \mathrm{~kb}$ region upstream of the TSS of the miR-183/-96/-182 cluster in vertebrates. (B) Luciferase activities were decreased after mutation of the first ZEB1 and HSF2 transcription factor binding sites. All luciferase activities were normalized to those obtained with the pGL3-Basic vector alone. Error bars represent SD $(n=3)$. (C) Transfection of ZEB1 and HSF2 transcription factors could elevate the luciferase activity of native upstream 1 kb luciferase reporter but not its mutants. All luciferase activities were normalized to those obtained with the native upstream $1 \mathrm{~kb}$ alone. Error bars represent standard deviation $(n=3)$. (D) Real-time PCR showing that miR-96 and miR-183 levels were increased in ZEB1 and HSF2 overexpressing MCF-7 cell lines. U6 snRNA was used as internal control. Error bars represent SD $(n=3)$.

the correlation dropped dramatically in tumor samples. Because the transcription of miR-183/-96/-182 was so fast in cancer, some pri-miRNA was not complete.

\section{Up-regulation of the miR-183/-96/-182 cluster increased cell proliferation and migration and changed the cell cycle profile}

To investigate the biological effects of miR-183/-96/-182 cluster up-regulation in the development and progression of breast cancer, we generated miR-96, miR-182 and miR183 overexpression cell lines in both MCF-7 and T47D cells (Additional file 1: Figure S1). Using MTT assays, we observed that the growth rates of all overexpression cell lines were increased as compared with that of empty vector control or non-transfected cells in both MCF-7 and T47D cells (Figure 4A). Furthermore, in colony formation assays, the increase of colony numbers in MCF-7 overexpression cell lines indicated that ectopically expression of the miR183/-96/-182 cluster in MCF-7 cells significantly enhanced anchorage-independent growth (Figure 4B). Furthermore, in both MCF-7 and T47D cells, in vitro wound-healing assays demonstrated that the migration abilities of miR-183, miR-96, and miR-182 overexpression cell lines were elevated, as the non-healed areas were smaller in overexpression cell lines than in control (empty vector) or nontransfected cells (Figure 4C).

To further explore the ability of the miR-183/-96/-182 cluster to promote cell proliferation, we analyzed the cell cycle profile of these overexpression cell lines. In both MCF-7 and T47D cells, flow cytometry results showed a small but significant decrease in the percentage of cells in the G2/M peak and a small but significant increase in the percentage of cells in the G1/G0 peak, the percentage of cells in the $\mathrm{S}$ phase was unaltered (Figure 5). These data 

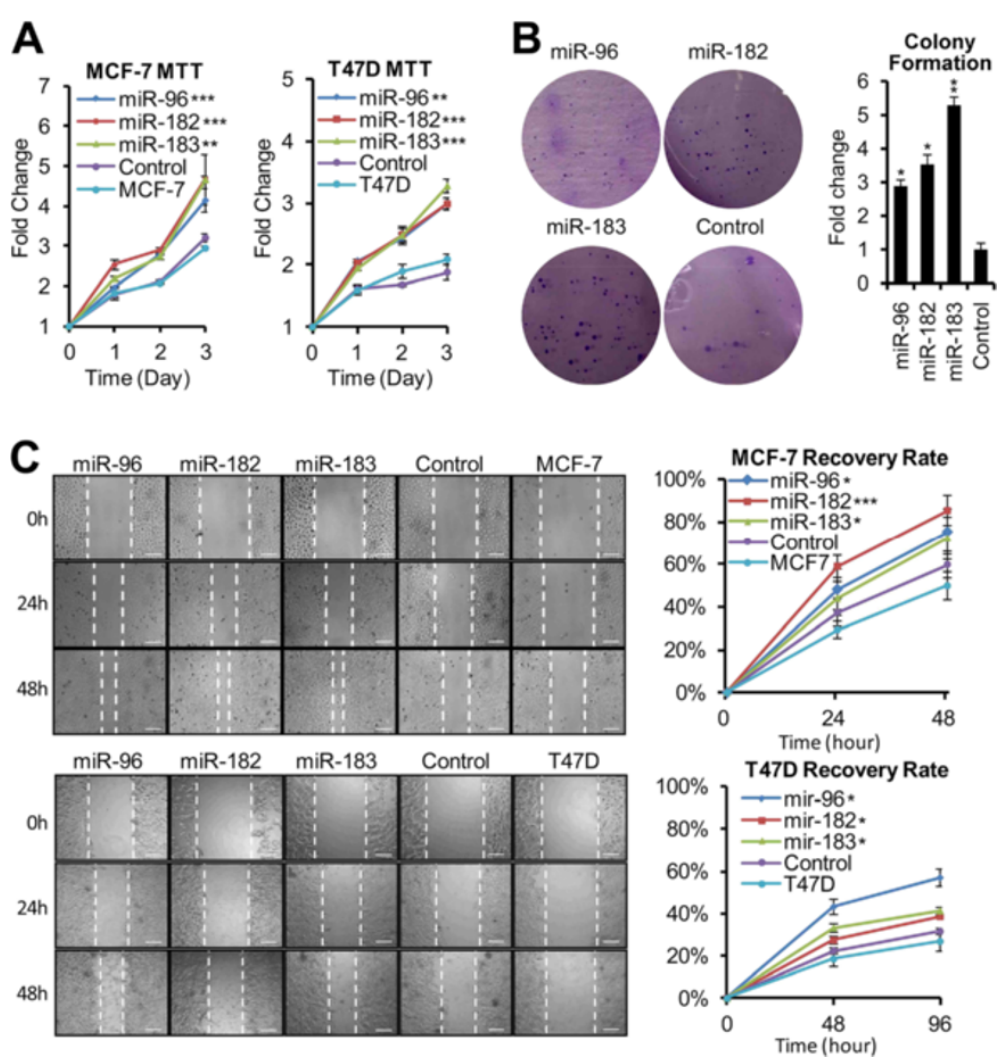

Figure 4 Up-regulation of the miR-183/-96/-182 cluster increased cell proliferation and migration. (A) The 3-(4, 5-dimethyl-2-thiazolyl)-2, 5-diphenyl-2H-tetrazolium bromide (MTT) assays showed that miR-183/-96/-182 cluster overexpression cell lines proliferated more rapidly than the vector control and non-infected cells. Error bars represent SD $(n=4)$. (B) Micrographs (left) and quantification (right) of crystal violet-stained cell colonies in miR-183/-96/-182 cluster overexpression MCF-7 cell lines and the vector control cells. Error bars represent SD ( $n=4)$. (C) Cell wound-healing assays demonstrated that the migration abilities of overexpression cell lines were elevated: left panel, representative micrographs; right panel, quantification graph; upper panel, MCF-7 cells; lower panel, T47D cells. Error bars represent SD $(n=4)$. Scale bars: $100 \mu m$.

suggest that the miR-183/-96/-182 cluster increased the cell proliferation by promoting more rapid completion of mitosis.

\section{Inhibition of miR-183/-96/-182 cluster miRNAs decreased} cell proliferation, and even induced cell death

To explore the knockdown effects of miR-183/-96/-182 cluster miRNAs, we transfected the miR-Down ${ }^{\mathrm{Tw}}$ antagomirs to the MCF-7 and T47D cells. First, we checked the knockdown efficiency and specificity of these antagomirs. Real-time PCR data showed that each antagomir knocked down its corresponding miRNA efficiently in both MCF-7 and T47D cells. MiR-182 antagomir also slightly decreased miR-96 expression, except that there were no crossreactions. The knockdown efficiency was higher in MCF-7 cells than in T47D cells, and miR-96 antagomir and miR182 antagomir were more efficient than $m i R-183$ antagomir (Figure 6A). Then, we checked the cell growth rates, cell migrations and cell cycle profiles of these knockdown cells by MTT assay, cell wound-healing assay and cell cycle analysis. MTT assay data showed that knockdown of
miR-96 and miR-182 decreased the cell growth rates significantly in both MCF-7 and T47D cells. The growth rate of miR-183 antagomir-treated cells also decreased slightly, but the decrease was not significant (Figure 6B). In MCF-7 cells, the migration abilities of knockdown cells were all decreased although the decrease was not significant for miR-183 antagomir-treated cells. However, in T47D cells, only the miR-182 antagomir led to the decrease of migration; the migration ability of miR-96 and miR-183 antagomir-treated cells remained the same (Figure 6C). Furthermore, cell cycle analysis demonstrated a significant increase in $\mathrm{G} 2 / \mathrm{M}$ phase and a decrease in $\mathrm{S}$ phase for cells treated with miR-182 antagomir in MCF-7 cells. Knockdown of miR-96 also decreased the percentage of cells in S phase slightly in MCF-7 cells, but in T47D cells the cell cycle profiles were not changed except for a slight increase in G2/M phase after miR-182 antagomir treatment (Figure 6D). We think the different behavior of MCF-7 and T47D cells after antagomir treatment was related to the knockdown efficiency. As the knockdown efficiency was higher in MCF-7 cells, the growth rate and 

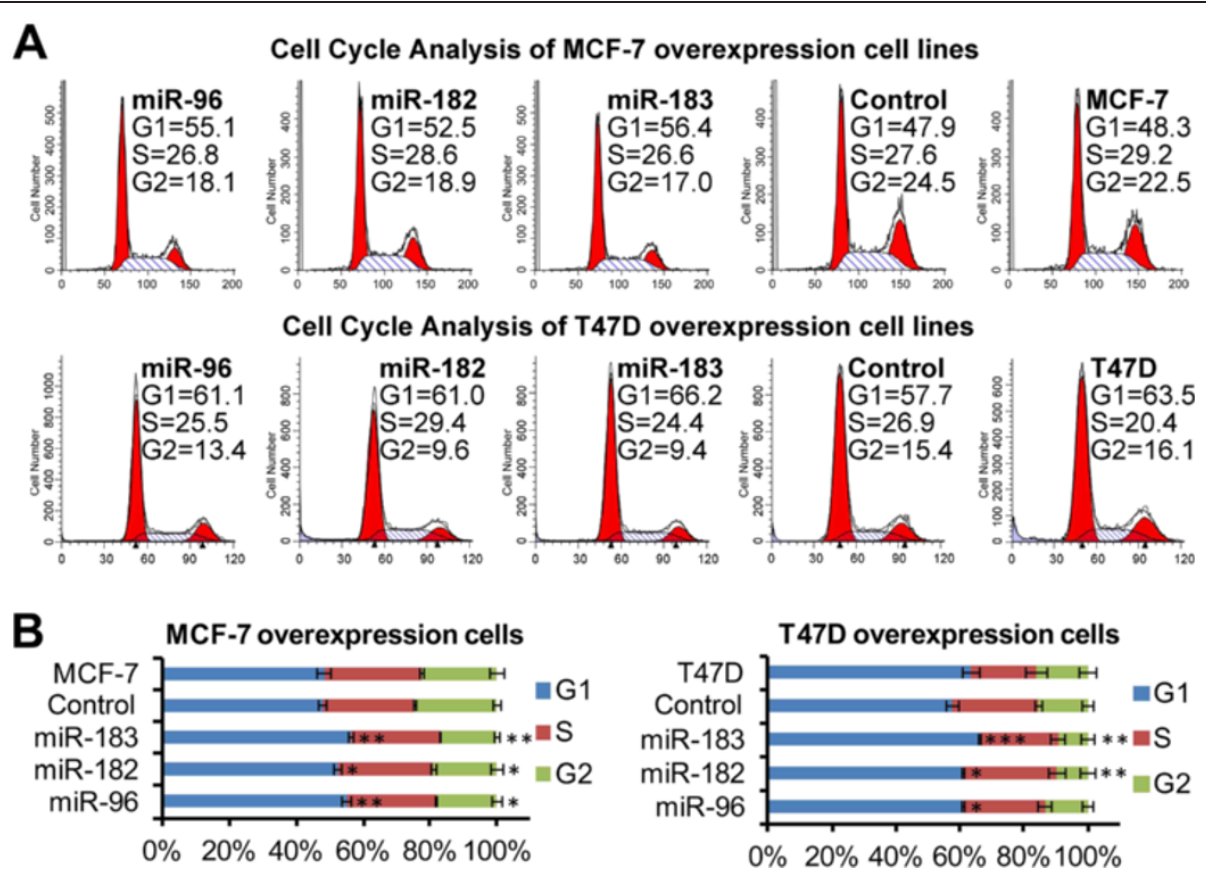

Figure 5 Up-regulation of miR-183/-96/-182 cluster miRNAs changed the cell cycle profile. Flow cytometric analysis showed a significant decrease in the percentage of cells in the G2/M peak and an increase in the percentage of cells in the G1/G0 peak of miR-183/-96/-182 cluster overexpression cell lines compared with the vector control cells and non-infected cells. (A) Representative flow cytometric graph of each cell line. (B) Quantification graph of the flow cytometric analysis. Error bars represent SD $(n=3)$.

migration ability of MCF-7 cells were seriously inhibited by the antagomir. Knockdown of miR-183 did not affect the cell profiles too much either in MCF-7 or in T47D cells. This phenomenon could be explained by the inefficient knockdown and the compensatory effect. MiR-96 and $m i R-182$ might have substituted partial function of $m i R-183$ and compensated the loss of $m i R-183$.

To further examine the biological effect of the $m i R$ $183 /-96 /-182$ cluster as a whole on breast cancer cells, we generated $m i R-183 /-96 /-182$ cluster sponge lentivirus (Additional file 2: Figure S2), and infected T47D cells with this vector. First, we checked the inhibition efficiency of this virus by real-time PCR. Compared to the empty vector, the expressions of $m i R-183 /-96 /-182$ cluster miRNAs were dropped to a half after sponge lentivirus transduction; and the expression of FOXO1, which was a generally acknowledged target gene of the $m i R-183 /-96 /-182$ cluster, was increased about 2-fold after sponge lentivirus transduction (Figure 6F upper panel). We found that T47D cells underwent cell death and apoptosis after transduction. Three days after transduction, the cells became round and detached (Figure 6E). Cell cycle analysis showed an increase in the percentage of cells in the G2/M peak and pre-G1 peak and a decrease in the percentage of cells in the G1/G0 peak, indicating that inhibition of miR-183/-96/-182 induced G2/M arrest and apoptosis (Figure 6F lower panel).
As MCF-7 and T47D cells are both luminal breast cancer, we also tested the miRNA knockdown effects in basal-like breast cancer cells, such as BT-20 (Basal A) and MDA-MB-231 (Basal B) cells. We found basal-like cells were more sensitive to the depletion of the $m i R$ 183/-96/-182 cluster than the luminal-like cells. MTT experiments showed BT-20 ceased proliferation and underwent cell death after knockdown of miR-96, miR-182 or miR-183 (Additional file 7: Figure S4A, B). MDA-MB-231 cells underwent cell death and apoptosis after transduction of $m i R-183 /-96 /-182$ cluster sponge lentivirus. The cells became round and detached 3 days after transduction, and the cell cycle analysis showed that pre-G1 cells, which represented the apoptotic cells, were increased in knockdown cells (Additional file 7: Figure S4C, D).

MiR-183 targeted the RAB21 gene directly in breast cancer To better understand the biological roles of the miR-183/96/-182 cluster miRNAs in breast cancer, we compiled a list of putative target genes of the $m i R-183 /-96 /-182$ cluster that were dysregulated in breast cancer by using three computational target prediction-algorithms: PicTar, TargetScan 5.1 and MicroCosm (Additional file 4: Table S2). As mammalian miRNAs regulate target genes predominantly by acting to decrease target mRNA levels [24], we first compared the mRNA levels of those genes between breast cancer sample and its NAT by real-time PCR with 

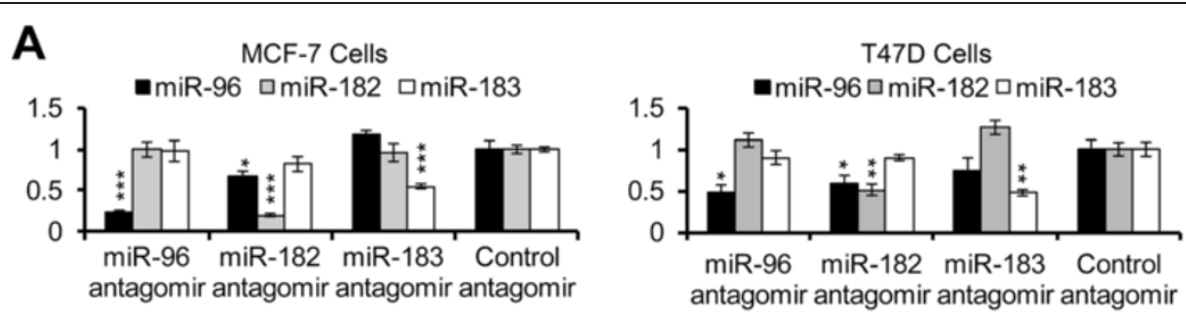

\section{B}
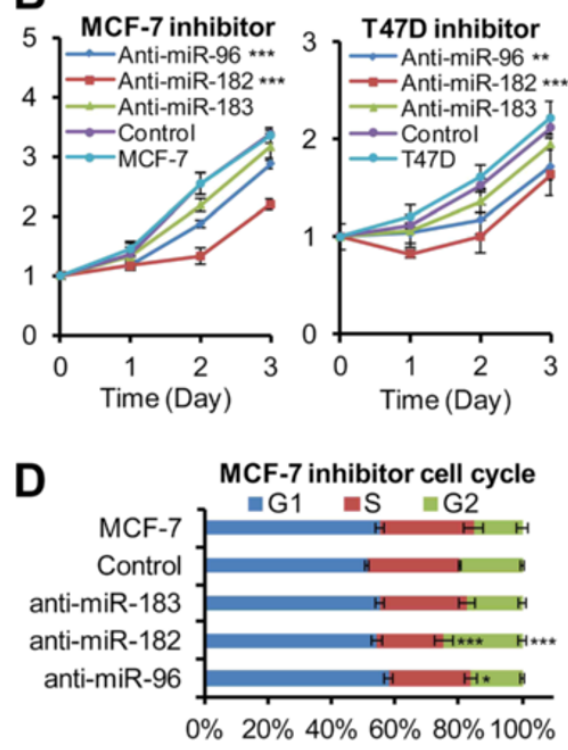

C
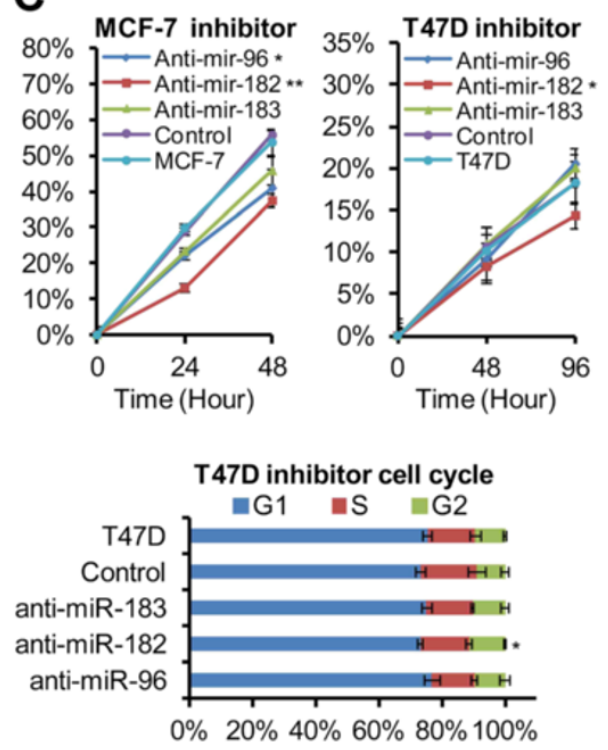
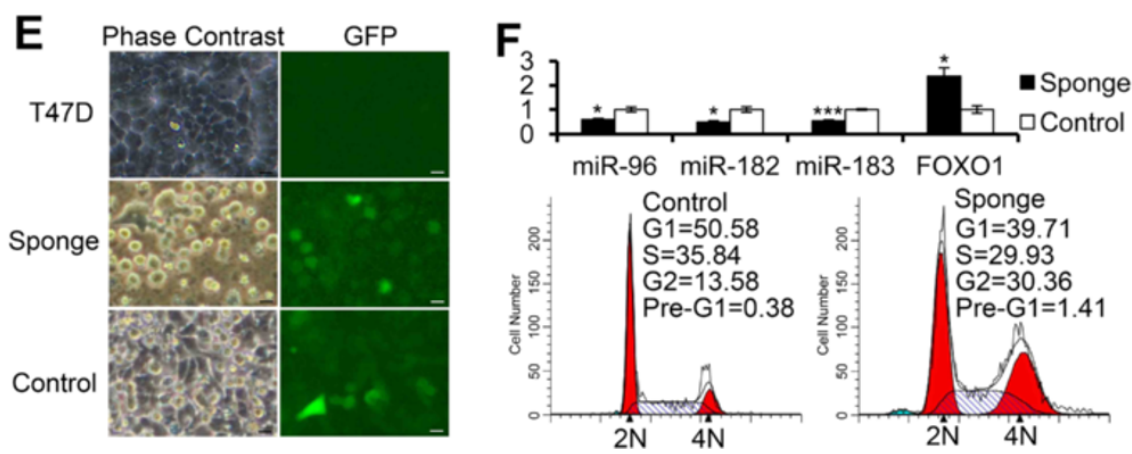

Figure 6 Inhibition of miR-183/-96/-182 cluster miRNAs decreased cell proliferation, and even induced cell death. (A) Real-time PCR results showed the knockdown efficiency and specificity of miR-Down ${ }^{\mathrm{TM}}$ antagomirs: left panel, MCF-7 cells; right panel, T47D cells. U6 snRNA was used as internal control. Error bars represent SD $(n=4)$. (B) The 3-(4, 5-dimethyl-2-thiazolyl)-2, 5-diphenyl-2H-tetrazolium bromide (MTT) assays showed the cell growth rates of miR-183/-96/-182 cluster knockdown cells. Error bars represent SD $(n=4)$. (C) Cell wound-healing assays showed the migration abilities of miR-183/-96/-182 cluster knockdown cells. Error bars represent SD $(n=4)$. (D) Flow cytometric analysis of miR-183/-96/-182 cluster knockdown cells. Error bars represent SD $(n=3)$. (E) T47D cells infected with miR-183/-96/-182 cluster sponge lentivirus underwent apoptosis 3 days after transduction: left panels, phase-contrast micrographs of indicated cells; right panels, green fluorescent micrographs of indicated cells. Scale bars: $20 \mu \mathrm{m}$. (F) Analysis of miR-183/-96/-182 cluster sponge lentivirus-infected T47D cells: upper panel, inhibition efficiency of miR-183/-96/-182 cluster sponge lentivirus shown by real-time PCR (error bars represent SD, $n=4$; lower panels, flow cytometric graph of indicated cells.

GAPDH used as an internal control. Eight genes out of twenty-five candidates showed significantly decreased expression in breast cancer (Figure 7A). To validate the eight candidates, we checked their mRNA levels in the miR-96, miR-182 and miR-183 MCF-7 overexpression cell lines.
Compared to empty vector control cells, $R A B 21$ was decreased in the miR-183 overexpression cell line; $R A B 40 B$ was decreased in $m i R-96$ and $m i R-183$ overexpression cell lines and TNFSF11 was decreased in the miR-96 overexpression cell line (Figure 7B). 

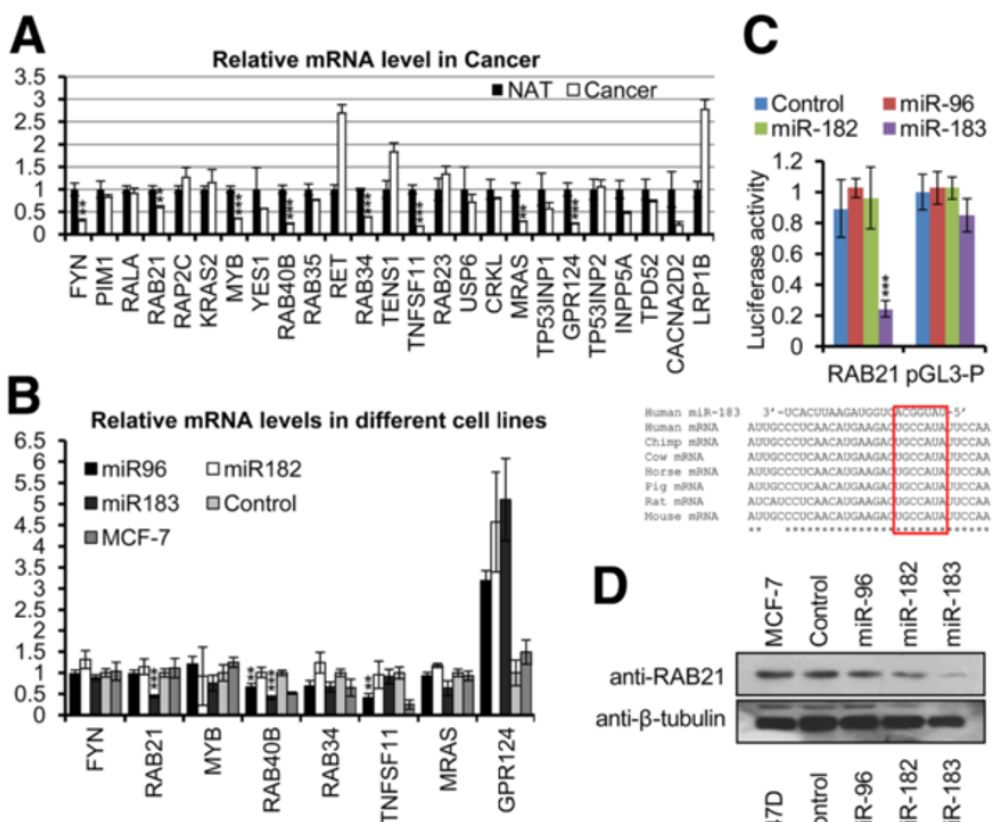

E
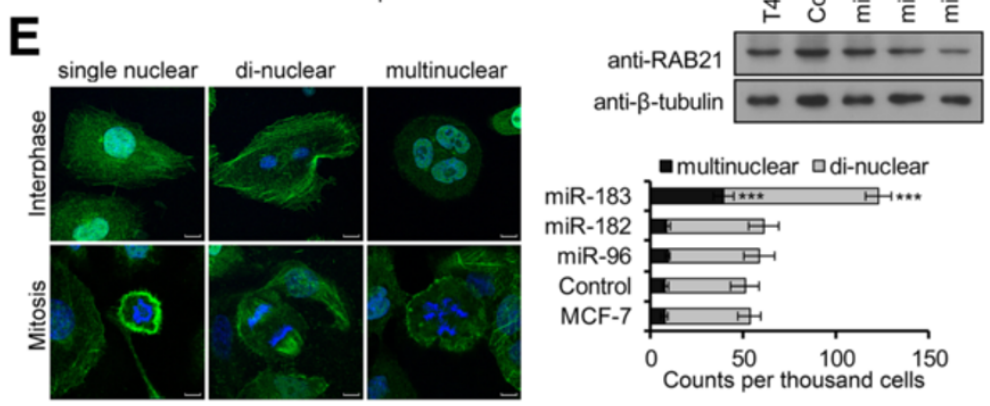

Figure 7 Identification of candidate targets of miR-183/-96/-182 cluster miRNAs. Predicted miR-183/-96/-182 targets are listed in Additional file 4: Table S2 where their NCBI reference sequence, putative binding miRs and detection primers are also provided. (A) Comparison of candidate target mRNA levels between breast cancer samples and their normal adjacent tissue (NAT) by real-time PCR; glyceraldehyde-3-phosphate dehydrogenase (GAPDH) was used as an internal control. Error bars represent SD $(n=3)$. (B) Confirmation of target genes by real-time PCR in miR-183/-96/-182 cluster overexpression stable MCF-7 cell lines and control cells; GAPDH was used as an internal control. Error bars represent SD $(n=3)$. (C) Confirmation of miR-183/-96/-182 cluster targets by luciferase assay. All data were normalized to those obtained with the pGL3-Promoter vector alone. Error bars represent SD $(n=3)$ : lower panel, sequences of miR-183 and its target sequences in the $3^{\prime}-U T R$ of different species. (D) Protein levels of RAB21 in stable cell lines were documented by western blot with an anti-RAB21 antibody. $\beta$-Tubulin was used as the internal control; upper panel, MCF-7 cells; lower panel, T47D cells. (E) Phalloidin and 4',6-diamidino-2-phenylindole (DAPI) counterstaining results showed that the bi- and multinuclear cells were accumulated in miR-183 over-expressed MCF-7 cells; left panels, representative micrographs of single, bi- and multinuclear cells in both interphase and mitosis; right panel, quantification of bi- and multinuclear cells in different cell lines. Error bars represent SD $(n=5)$. Scale bars: $10 \mu \mathrm{m}$.

Because $R A B 21$ was the predicted target gene of $m i R$ 183 , we focused our efforts on this target. $R A B 21$, which belongs to the $R a b$ family of monomeric GTPases, plays a role in integrin internalization and recycling. As a result, the encoded protein is involved in cytokinesis during the mitosis. Loss of RAB21 in the tumor induces chromosome number aberrations and malignancy [25]. To further evaluate the role of $m i R-183$ in regulating $R A B 21$, we generated luciferase reporters with $33 \mathrm{bp}$ of the predicted target regions from the 3 '-UTR of RAB21, and co-transfected the reporter with $m i R-96, m i R-182$ and $m i R-183$ overexpression vectors and empty vector. The luciferase assay results showed that $m i R-183$ repressed luciferase activity dramatically in the reporter derived from the $R A B 21$-targeted region compared with the empty vector, and $m i R-96$ and $m i R-182$ had no effect on the luciferase activity of the $R A B 21$ reporter. As a negative control, the luciferase activity of cells containing the empty pGL3Promoter vector was not affected by any miR-183/-96/182 cluster miRNA (Figure 7C). The protein levels of RAB21 were also determined in both MCF-7 and T47D overexpression cell lines with $\beta$-tubulin used as an internal 
control. The data showed that $R A B 21$ protein was significantly decreased in the $m i R-183$ overexpression cell lines, but not in miR-96 and miR-182 overexpression cell lines compared with the empty vector control cell lines and wild-type cells (Figure 7D). As loss of RAB21 in the tumor would induce chromosome number aberrations, we checked the nucleus aberration in miR-183/-96/-182 cluster overexpression MCF-7 cells. Phalloidin and DAPI counterstaining results showed that the bi- and multinuclear cells were accumulated in miR-183 overexpressed cells but not in miR-96 and miR-182 overexpressed cells (Figure 7E). All these data indicated that miR-183 targeted the $R A B 21$ gene directly in breast cancer and induced aneuploidy.

\section{Discussion}

The MiR-183/-96/-182 cluster is a conserved polycistronic miRNA cluster that is highly expressed in several tumor types. Although it is well known that the expression level of this miRNA cluster is increased in breast cancer, its biological roles and the regulatory mechanisms governing MiR-183/-96/-182 expression in breast cancer are still unclear. Here, we report that miR-96, $m i R-182$ and $m i R-183$ expression levels are significantly higher in breast cancer compared to the NAT, and the transcription pattern of miR-183/-96/-182 is irregular in breast cancer as the correlation between $m i R-182$ and miR-183 expression dropped dramatically in tumor samples. The expression of miR-183/-96/-182 is not upregulated in a specific breast cancer subtype. It is overexpressed in all kinds of breast cancer - ductal or lobular, luminal or basal, early-stage or late-stage - but there are some differences in their expression patterns. For example, $m i R-96$ and $m i R-183$ were lower in lobular carcinoma than in ductal carcinoma and other types of carcinoma. The levels of $m i R-96$ and $m i R-183$ were also lower in ER+ and PR+ cancers than in ER- and PR- cancers, but miR-182 was almost the same, even a little higher in ER+ cancers. Among the four different subtypes of breast cancer, miR-96 and miR-183 levels were higher in HER2-enriched breast cancers than other types; miR-182 was lower but miR-183 was higher in basal-like breast cancers than other types of breast cancer. We also compared the miRNA expression levels in different breast cancer cell lines based on their molecular markers. We found that miR-96 is only upregulated in SK-BR-3 and BT-20 cells, whereas $m i R-182$ and $m i R-183$ are upregulated in most of the breast cancer cell lines tested except for MDA-MB-231. Basically, the cell line data closely match the clinical analysis. MiR-96 and miR-183 levels are higher in HER2-enriched cell line SK-BR-3. MiR-96 is lower in $\mathrm{ER}+$ and $\mathrm{PR}+$ cancers than in ER- and PR- cancers. MiR-182 is higher in luminal breast cancer than basal breast cancer. MDA-MB-231 is the only exception. It is an ER- and PR- cancers, but its expression of miR183/-96/-182 is low. Because MDA-MB-231 is a basal B/ claudin-low breast cancer cell line, which lacks common epithelial cell features and most closely resembles the mammary epithelial stem cell [26], we think its regulation of miR-183/-96/-182 is different to other breast cancer cell lines. Our data were similar to those reported by Riaz and colleagues. Based on their work, 51 human breast cancer cell lines were divided into two groups: the first major group included 33 cell lines, which was a luminal-like group; the second minor group included 18 cell lines, which was a basal-like group. Seventeen miRNAs, which included miR-182, showed significantly higher expression in the major cluster compared with the other miRNAs. They also found that the expression of miR-183/96/-182 is low in MDA-MB-231 cells [23]. Although the miR-183/-96/-182 cluster is transcribed in the same primiRNA, the expression profile of each miRNA varies between different cell lines, which indicate that their subsequent processing or stability are regulated in different ways. An interesting phenomenon is that from the 102 patient samples of TCGA dataset, miR-182 only increases 4.2 ( \pm 1.1)-fold in tumor samples, but $m i R-96$ and $m i R$ 183 increase 8.4 ( \pm 1.1 )- and 7.5 ( \pm 1.1$)$-fold in tumor samples. The correlation between the expressions of $m i R$ 182 and $m i R-183$ dropped dramatically in tumor samples. This phenomenon was also confirmed in HSF2 and ZEB1 overexpression cell lines, as the expressions of $m i R-96$ and miR-183 were increased significantly, but not miR-182. We think it is because the transcription of miR-183/-96/182 is very fast in cancer; some pri-miRNA is not complete and the transcription stalls before miR-182.

We also identified two transcriptional factors that regulate the transcription of the miR-183/-96/-182 cluster, ZEB1 and HSF2. ZEB1, which is a zinc finger transcription factor, is involved in the epithelial-mesenchymal transition and promotes metastasis in cancer $[27,28]$. Although most work has concentrated on the capacity of $Z E B 1$ to repress gene expression, several groups demonstrated that $Z E B 1$ can also activate transcription of downstream targets [28,29]. HSF2 binds heat shock promoter elements (HSE) and activates transcription. Although there is little evidence on the involvement of $H S F 2$ in tumorigenesis, it can play a role indirectly by modulating HSF1 [30]. Previous studies also report that $H S F 2$ regulates the proto-oncogene c-fos and may be involved in tumorigenesis [31]. Our findings show that ZEB1 and $H S F 2$ activate the transcription of the miR-183/-96/-182 cluster, which gives us new insights into how ZEB1 and HSF2 enhance tumorigenesis.

The biological role of the miR-183/-96/-182 cluster in breast cancer is complicated. In our experience, this cluster functions more like an oncogene in breast cancer as it increases cancer cell proliferation and migration. Most previous and recent publications support this conclusion, 
especially for miR-182, which has been confirmed by many groups to induce breast cancer metastasis [6,32-34]. Mir-96 is also proposed to be an onco-miRNA in breast cancer [5,6], but the role of $m i R-183$ is more complex. It represses the expression of EGR1 and functions as an oncogene in breast cancer [35], but it also targets the Ezrin gene and inhibits cell migration in T47D cells [12]. Our results support a pro-oncogenic role for $m i R-183$ in breast cancer, because upregulated expression of $m i R-183$ by lentivirus in MCF-7 cells induces cell proliferation and migration. The effects of knockdown of $m i R-183 /-96 /-182$ cluster are more complicated, and depend on the knockdown efficiency and specificity. We did not observe obvious changes after inhibition of $m i R-183$, but we found a significant decrease in cell growth rates and $S$ phase cell percentages in miR-96 and miR-182-inhibited cells. Two reasons can explain these results. First, the knockdown efficiency of $m i R-183$ antagomir is lower than $m i R-96$ and $m i R-182$ antagomir. Second, $m i R-96$ and $m i R-182$ target FOXO1, but $m i R-183$ does not [6]. MiR-96 and $m i R-182$ might compensate partial functions of $m i R-183$, but $m i R$ 183 cannot replace the function of $m i R-96$ and $m i R-182$ on inhibition of FOXO1.

Long-term inhibition of three miRNAs by sponge elements induced cell death and apoptosis in T47D cells, but we did not detect apoptosis with a single antagomir transfection. Inhibition of two or three of the cluster members at one time induced apoptosis, though some of them were not statistically significant (Additional file 8: Figure S5). These data indicate that these three miRNAs are redundant; they may be complimentary to each other. Knockdown of $m i R-183$ had little effect on its own, but it had collaborative effects with the other two miRNAs.

We identified $R A B 21$ as a target gene of miR-183 in both mRNA and protein levels, and also confirmed that overexpression of $m i R-183$ induced accumulation of biand multinuclear cells. $R A B 21$ is involved in the targeted trafficking of integrins via its association with integrin alpha tails. As a consequence, $R A B 21$ regulates cell adhesion and migration [36]. In mitotic cells, integrin trafficking regulated by $R A B 21$ is necessary for cytokinesis and cytokinesis failure will induce aneuploidy and oncogenic transformation [25,37]. This information may answer the question why $m i R-183$ has dual effects in breast cancer. In some cases, repression of $R A B 21$ results in decreased cell mobility, but in other cases, repression of $R A B 21$ may lead to cytokinesis failure and aneuploidy. The 3'-UTR of $R A B 21$ matches the seed sequence of $m i R-183$, but not $m i R-96$ nor $m i R-182$. So, only $m i R-183$ can inhibit the expression of $R A B 21$. As the phenotype is similar no matter which of the three miRNAs is overexpressed in MCF-7 and T47D cells, RAB21 down regulation itself is not enough to explain the phenotype. Some other mechanisms are also involved in the regulation of cell proliferation and migration. For example, inhibition of FOXO1 by $m i R-96$ and $m i R-182$ will increase cell proliferation.

We identified two regulators (ZEB1 and HSF2) and one target gene $(R A B 21)$ for the $m i R-183 /-96 /-182$ cluster in breast cancer cell lines. How do they work in clinical samples? We looked for correlation between $m i R-183 /-96 /-182$ cluster miRNAs and their target/regulators by analysis of 508 clinical samples from TCGA data (Additional file 9). Because the correlations between miRNAs and their targets/regulators are not simply negative or positive correlations, we did not find any direct correlations between these miRNAs and the expressions of HSF2, ZEB1 and $R A B 21$ based on the TCGA data analysis. But there were some interesting correlations between them in different subtypes. MiR-96 and miR-183 weree lower in ER+ and $\mathrm{PR}+$ breast cancers than ER- and PR- breast cancers; in the meantime, their regulator, HSF2 level was lower and their target, $R A B 21$ level, was higher in ER+ and $\mathrm{PR}+$ breast cancers than ER- and PR- breast cancers (Additional file 4: Table S4). Subtype analysis also confirmed our findings. HSF2 level was high in basal breast cancers, which are miR-183-enriched breast cancers; and $R A B 21$ level was low in HER2 and basal breast cancers, which are $m i R-96$ - and/or $m i R$-183-enriched breast cancers (Additional file 4: Table S5). MiR-182 was not strongly correlated with the levels of HSF2 because its transcription is not controlled by HSF2 (Figure 3D). There is still a complicated phenomenon that requires explanation, which is that the ZEB1 level was negatively correlated with miR-96 and $m i R-183$ (Additional file 4: Table S4, S5). In MCF-7 cells, ZEB1 upregulates the expressions of miR-96 and miR-183 (Figure 3), and Graham et al. also report that ZEB1 is more expressed in ER/PR- breast cell lines than $\mathrm{ER} / \mathrm{PR}+$ breast cell lines [38]. However, in clinical samples, $Z E B 1$ was enriched in ER/PR+ samples. Considering ZEB1 is a transcription factor that can either activate or repress its target genes, we think it functions differently in breast cancer cell lines and breast cancer patients. In patients, ZEB1 may repress the transcription of $m i R-183 /-96 /-182$ cluster. This conclusion needs further work for confirmation, but nevertheless, ZEB1 plays an important role in the regulation of $m i R-183 /-96 /-182$ cluster.

\section{Conclusion}

We found that the miR-183/-96/-182 cluster is highly expressed in most breast cancers, and its transcription is disordered in breast cancers. The miR-183/-96/-182 cluster is transcribed in the same pri-miRNA and its transcription is regulated by $Z E B 1$ and $H S F 2$. It increases breast cancer cell proliferation, promotes cell migration and is essential for cell survival. Also, $m i R-183$ targets the $R A B 21$ gene directly in breast cancer. In summary, the $m i R-183 /-96 /-182$ cluster is upregulated in most breast cancers. It functions as 
an oncogene in breast cancer as it increases cell proliferation and migration. This can be partially explained by the inhibition of tumor suppressor gene RAB21.

The bioinformatics tools used in this manuscript were the miRBase Sequence Database [39]; the TCGA dataset [40]; the ENCODE Project [41]; TFSEARCH [42]; PicTar [43]; TargetScan 5.1 [44], and MicroCosm [45].

\section{Additional files}

Additional file 1: Figure S1. Creation of miR-183/96/182 stable cell lines. Additional file 2: Figure S2. Creation of miR-183/96/182 cluster sponge lentivirus.

Additional file 3: Figure S3. Test of the specificity of cluster probes by LNA-based Northern Blot.

Additional file 4: Supplementary tables. Table S1. miRNA mimics used in LNA-based northern blot. Table S2. Primer sets for predicted miR-183/-96/-182 cluster target genes. Table S3. Primer sets for pri-miRNA transcription screening. Table $\mathbf{S 4}$. The correlations between miRNAs targets/regulators and surface markers. Table S5. miRNAs' targets/regulators in different molecular subtypes of breast cancer.

Additional file 5: MiRNAs in breast cancers and their matched normal controls.

Additional file 6: Clinical features and miRNAs.

Additional file 7: Figure S4. Test of the miRNA knockdown effects in basal-like breast cancer cells.

Additional file 8: Figure S5. Inhibition two or three of the cluste members at one time induced apoptosis in T47D cells.

Additional file 9: Targets and regulators.

\section{Abbreviations}

BAC: bacterial artificial chromosome; bp: base pairs; ChIP: chromatin immunoprecipitation; CT: cycle threshold; DAPI: 4',6-diamidino-2phenylindole; DMEM: Dulbecco's modified Eagle's medium; DMSO: dimethyl sulphoxide; ELISA: enzyme-linked immunosorbent assay; ER: estrogen receptor; FBS: fetal bovine serum; FOXO: forkhead box O; GFP: green fluorescent protein; HER2: human epidermal growth factor receptor-2; HSE: heat shock promoter elements; miRNA: microRNA; MOI: multiplicity of infection; MTT: 3-(4, 5-dimethyl-2-thiazolyl)-2, 5-diphenyl-2H-tetrazolium bromide; NAT: normal adjacent tissues; NBEC: normal breast epithelial cells; PBS: phosphate-buffered saline; PI: propidium iodide; PR: progesterone receptor; RT: reverse transcription; TSS: transcription start site; UTR: untranslated region.

\section{Competing interests}

The authors declare that they have no competing interests.

\section{Authors' contributions}

PL carried out the molecular and cellular biology studies and drafted the manuscript. CS participated in the construction of plasmids and viruses. LLH participated in cellular biology studies. HZ collected cancer samples. LHH conducted real-time PCR and FACS. ZC participated in the design of the study and performed the statistical analysis. QZ conceived of the study, and participated in its design and coordination and helped to draft the manuscript. All authors read and approved the final manuscript.

\section{Authors' information}

$\mathrm{QZ}$ is a geneticist and molecular biologist whose research interests focus on cancer and stem cells. Dr QZ received his BSc degree from Wuhan University, China (2003) and his PhD from Texas A\&M University, Houston, USA (2009) where he studied signal pathways in cancer and stem cells. Dr QZ performed his postdoctoral training at the department of pharmacology in Case Western Reserve University where he started to work on microRNA. He became Associate Professor in 2011 at the School of Pharmaceutical Science in Central South University, China, and got the foundation from
National Natural Science Foundation of China in 2012. QZ is a member of the Chinese Pharmacological Society and his recent work focuses on the roles of microRNA in cancer.

\section{Acknowledgements}

We thank Hunan Tumor Hospital (Changsha, China) for providing the tumor samples and the Department of Hematology in the third Xiangya Hospital (Changsha, China) for performing the flow cytometry. We also thank NeuronBiotech Co. (Shanghai, China) for creation of lentivirus and stable cell lines. This research is supported by National Natural Science Foundation of China, for Grant C0709- 31201056, Functional studies of miR-183/-96/-182 cluster in breast cancer diagnosis and treatment.

\section{Author details}

${ }^{1}$ The School of Pharmaceutical Sciences in Central South University, 172 Tongzipo Road, Yuelu District, Changsha 410013, Hunan, China. ${ }^{2}$ The Third Xiangya Hospital of Central South University, Changsha 410013, Hunan, China.

Received: 17 December 2013 Accepted: 28 October 2014

Published online: 14 November 2014

\section{References}

1. Xu S, Witmer PD, Lumayag S, Kovacs B, Valle D: MicroRNA (miRNA) transcriptome of mouse retina and identification of a sensory organ-specific miRNA cluster. J Biol Chem 2007, 282:25053-25066.

2. $X u D, \mathrm{He} X$, Chang $Y, X_{u} C$, Jiang $X$, Sun $S$, Lin J: Inhibition of miR-96 expression reduces cell proliferation and clonogenicity of HepG2 hepatoma cells. Oncol Rep 2013, 29:653-661.

3. Mihelich BL, Khramtsova EA, Arva N, Vaishnav A, Johnson DN, Giangreco AA, Martens-Uzunova E, Baqasra O, Kajdacsy-Balla A, Nonn L: miR-183-96-182 cluster is overexpressed in prostate tissue and regulates zinc homeostasis in prostate cells. J Biol Chem 2011, 286:44503-44511.

4. Weeraratne SD, Amani V, Teider N, Pierre-Francois J, Winter D, Kye MJ, Senqupta S, Archer T, Remke M, Bai AH, Warren P, Pfister SM, Steen JA, Pomeroy SJ, Cho YJ: Pleiotropic effects of miR-183 96 182 converge to regulate cell survival, proliferation and migration in medulloblastoma. Acta Neuropathol 2012, 123:539-552.

5. Lin H, Dai T, Xiong H, Zhao X, Chen X, Yu C, Li J, Wang X, Song L: Unregulated miR-96 induces cell proliferation in human breast cancer by downregulating transcriptional factor FOXO3a. PLoS One 2010, 5:e15797.

6. Guttilla IK, White BA: Coordinate regulation of FOXO1 by miR-27a, miR-96, and miR-182 in breast cancer cells. J Biol Chem 2009, 284:23204-23216.

7. Song L, Liu L, Wu Z, Li Y, Ying Z, Lin C, Wu J, Hu B, Cheng SY, Li M, Li J: TGF-beta induces miR-182 to sustain NF-kappaB activation in glioma subsets. J Clin Invest 2012, 122:3563-3578.

8. Segura MF, Hanniford D, Menendez S, Reavie L, Zou X, Alvarez-Diaz S, Zakrzewski J, Blochin E, Rose A, Boqunovic D, Polsky D, Wei J, Lee P, Belitskaya-Levy I, Bhardwaj N, Osman I, Hernando E: Aberrant miR-182 expression promotes melanoma metastasis by repressing $\mathrm{FOXO} 3$ and microphthalmia-associated transcription factor. Proc Natl Acad Sci U S A 2009, 106:1814-1819.

9. Sarver AL, Li L, Subramanian S: MicroRNA miR-183 functions as an oncogene by targeting the transcription factor EGR1 and promoting tumor cell migration. Cancer Res 2010, 70:9570-9580.

10. Li J, Fu H, Xu C, Tie Y, Xing R, Zhu J, Qin Y, Sun Z, Zheng X: miR-183 inhibits TGF-beta1-induced apoptosis by downregulation of PDCD4 expression in human hepatocellular carcinoma cells. BMC Cancer 2010, 10:354.

11. Yu S, Lu Z, Liu C, Meng Y, Ma Y, Zhao W, Liu J, Yu J, Chen J: miRNA-96 suppresses KRAS and functions as a tumor suppressor gene in pancreatic cancer. Cancer Res 2010, 70:6015-6025.

12. Lowery AJ, Miller N, Dwyer RM, Kerin MJ: Dysregulated miR-183 inhibits migration in breast cancer cells. BMC Cancer 2010, 10:502.

13. Zhu J, Feng $Y$, Ke Z, Yang Z, Zhou J, Huang $X$, Wang L: Down-regulation of miR-183 promotes migration and invasion of osteosarcoma by targeting Ezrin. Am J Pathol 2012, 180:2440-2451.

14. Sun Y, Fang R, Li C, Li L, Li F, Ye X, Chen H: Hsa-mir-182 suppresses lung tumorigenesis through down regulation of RGS17 expression in vitro. Biochem Biophys Res Commun 2010, 396:501-507. 
15. Lee Y, Kim M, Han J, Yeom KH, Lee S, Baek SH, Kim VN: MicroRNA genes are transcribed by RNA polymerase II. EMBO J 2004, 23:4051-4060.

16. Ozsolak F, Poling LL, Wang Z, Liu H, Liu XS, Roeder RG, Zhang X, Song JS, Fisher DE: Chromatin structure analyses identify miRNA promoters. Genes Dev 2008, 22:3172-3183.

17. Saini HK, Griffiths-Jones S, Enright AJ: Genomic analysis of human microRNA transcripts. Proc Natl Acad Sci U S A 2007, 104:17719-17724.

18. Wang G, Wang $Y$, Shen $C$, Huang $Y W$, Huang $K$, Huang $T H$, Nephew KP, Li L, Liu Y: RNA polymerase II binding patterns reveal genomic regions involved in microRNA gene regulation. PLoS One 2010, 5:e13798.

19. Chien CH, Sun YM, Chang WC, Chiang-Hsieh PY, Lee TY, Tsai WC, Horng JT, Tsou AP, Huang HD: Identifying transcriptional start sites of human microRNAs based on high-throughput sequencing data. Nucleic Acids Res 2011, 39:9345-9356.

20. Ebert MS, Neilson JR, Sharp PA: MicroRNA sponges: competitive inhibitors of small RNAs in mammalian cells. Nat Methods 2007, 4:721-726.

21. Zhu Q, Sun W, Okano K, Chen Y, Zhang N, Maeda T, Palczewski K: Sponge transgenic mouse model reveals important roles for the microRNA-183 (miR-183)/96/182 cluster in postmitotic photoreceptors of the retina. J Biol Chem 2011, 286:31749-31760

22. Razzaghi H, Troester MA, Gierach GL, Olshan AF, Yankaskas BC, Millikan RC: Association between mammographic density and basal-like and luminal A breast cancer subtypes. Breast Cancer Res 2013, 15:R76.

23. Riaz M, van Jaarsveld MT, Hollestelle A, Prager-van der Smissen WJ, Heine AA, Boersma AW, Liu J, Helmijr J, Ozturk B, Smid M, Wiemer EA, Foekens JA, Martens JW: miRNA expression profiling of 51 human breast cancer cell lines reveals subtype and driver mutation-specific miRNAs. Breast Cancer Res 2013, 15:R33.

24. Guo H, Ingolia NT, Weissman JS, Bartel DP: Mammalian microRNAs predominantly act to decrease target mRNA levels. Nature 2010, 466:835-840.

25. Hognas G, Tuomi S, Veltel S, Mattila E, Murumagi A, Edgren H, Kallioniemi O, Ivaska J: Cytokinesis failure due to derailed integrin traffic induces aneuploidy and oncogenic transformation in vitro and in vivo. Oncogene 2012, 31:3597-3606.

26. Prat A, Parker JS, Karginova O, Fan C, Livasy C, Herschkowitz Jl, He X, Perou CM: Phenotypic and molecular characterization of the claudin-low intrinsic subtype of breast cancer. Breast Cancer Res 2010, 12:R68.

27. Spaderna S, Schmalhofer O, Wahlbuhl M, Dimmler A, Bauer K, Sultan A, Hlubek F, Jung A, Strand D, Eger A, Kirchner T, Behrens J, Brabletz T: The transcriptional repressor ZEB1 promotes metastasis and loss of cell polarity in cancer. Cancer Res 2008, 68:537-544.

28. Chaffer CL, Marjanovic ND, Lee T, Bell G, Kleer CG, Reinhardt F, D'Alessio AC, Young RA, Weinberg RA: Poised chromatin at the ZEB1 promoter enables breast cancer cell plasticity and enhances tumorigenicity. Cell 2013, 154:61-74.

29. Dillner NB, Sanders MM: Transcriptional activation by the zinc-finger homeodomain protein delta EF1 in estrogen signaling cascades. DNA Cell Biol 2004, 23:25-34.

30. Sandqvist A, Bjork JK, Akerfelt M, Chitikova Z, Grichine A, Vourc'h C, Jolly C, Salminen TA, Nymalm Y, Sistonen L: Heterotrimerization of heat-shock factors 1 and 2 provides a transcriptional switch in response to distinct stimuli. Mol Biol Cell 2009, 20:1340-1347.

31. Wilkerson DC, Skaggs HS, Sarge KD: HSF2 binds to the Hsp90, Hsp27, and c-Fos promoters constitutively and modulates their expression. Cell Stress Chaperones 2007, 12:283-290.

32. Lei R, Tang J, Zhuang X, Deng R, Li G, Yu J, Liang Y, Xiao J, Wang HY, Yang Q, Hu G: Suppression of MIM by microRNA-182 activates RhoA and promotes breast cancer metastasis. Oncogene 2014, 33:1287-1296.

33. Liu H, Wang Y, Li X, Zhang YJ, Li J, Zheng YQ, Liu M, Song X, Li XR: Expression and regulatory function of miRNA-182 in triple-negative breast cancer cells through its targeting of profilin 1. Tumour Biol 2013, 34:1713-1722

34. Chiang $\mathrm{CH}$, Hou MF, Hung WC: Up-regulation of miR-182 by beta-catenin in breast cancer increases tumorigenicity and invasiveness by targeting the matrix metalloproteinase inhibitor RECK. Biochim Biophys Acta 2013, 1830:3067-3076.

35. Hannafon BN, Sebastiani P, de las Morenas A, Lu J, Rosenberg CL: Expression of microRNA and their gene targets are dysregulated in preinvasive breast cancer. Breast Cancer Res 2011, 13:R24.
36. Pellinen T, Arjonen A, Vuoriluoto K, Kallio K, Fransen JA, Ivaska J: Small GTPase Rab21 regulates cell adhesion and controls endosomal traffic of beta1-integrins. J Cell Biol 2006, 173:767-780.

37. Pellinen T, Tuomi S, Arjonen A, Wolf M, Edgren $H$, Meyer $H$, Grosse $R$, Kitzing JK, Kallioniem O, Fassler R, Kallio M, Ivaska J: Integrin trafficking regulated by Rab21 is necessary for cytokinesis. Dev Cell 2008, 15:371-385

38. Graham TR, Yacoub R, Taliaferro-Smith L, Osunkoya AO, Odero-Marah VA Liu T, Kimbro KS, Sharma D, O'Regan RM: Reciprocal regulation of ZEB1 and AR in triple negative breast cancer cells. Breast Cancer Res Treat 2010, 123:139-147.

39. miRBase Sequence Database [http://microrna.sanger.ac.uk/]

40. TCGA dataset [http://cancergenome.nih.gov/]

41. ENCODE Project [http://genome.ucsc.edu/ENCODE/]

42. TFSEARCH [http://www.cbrc.jp/research/db/TFSEARCH.html]

43. PicTar [http://pictar.mdc-berlin.de/]

44. TargetScan 5.1 [http://www.targetscan.org]

45. MicroCosm [http://www.ebi.ac.uk]

doi:10.1186/s13058-014-0473-z

Cite this article as: Li et al.: MiR-183/-96/-182 cluster is up-regulated in most breast cancers and increases cell proliferation and migration. Breast Cancer Research 2014 16:473.

\section{Submit your next manuscript to BioMed Central and take full advantage of:}

- Convenient online submission

- Thorough peer review

- No space constraints or color figure charges

- Immediate publication on acceptance

- Inclusion in PubMed, CAS, Scopus and Google Scholar

- Research which is freely available for redistribution 